\title{
Detection of H3K4me3 Identifies NeuroHIV Signatures, Genomic Effects of Methamphetamine and Addiction Pathways in Postmortem HIV+ Brain Specimens that Are Not Amenable to Transcriptome Analysis
}

\author{
Liana Basova ${ }^{1}$, Alexander Lindsey ${ }^{1}$, Anne Marie McGovern ${ }^{1}$, Ronald J. Ellis ${ }^{2}$ \\ and Maria Cecilia Garibaldi Marcondes ${ }^{1, *(D)}$ \\ 1 San Diego Biomedical Research Institute, San Diego, CA 92121, USA; lbasova@sdbri.org (L.B.); \\ alindsey@SDBRI.ORG (A.L.); annemariermcgovern@gmail.com (A.M.M.) \\ 2 Departments of Neurosciences and Psychiatry, University of California San Diego, San Diego, CA 92103, USA; \\ roellis@health.ucsd.edu \\ * Correspondence: cmarcondes@SDBRI.org
}

Citation: Basova, L.; Lindsey, A.; McGovern, A.M.; Ellis, R.J.; Marcondes, M.C.G. Detection of H3K4me3 Identifies NeuroHIV Signatures, Genomic Effects of Methamphetamine and Addiction Pathways in Postmortem HIV+ Brain Specimens that Are Not Amenable to Transcriptome Analysis. Viruses 2021, 13, 544. https://doi.org/10.3390/ v13040544

Academic Editor: Stefano Aquaro

Received: 17 February 2021

Accepted: 22 March 2021

Published: 24 March 2021

Publisher's Note: MDPI stays neutral with regard to jurisdictional claims in published maps and institutional affiliations.

Copyright: (c) 2021 by the authors. Licensee MDPI, Basel, Switzerland. This article is an open access article distributed under the terms and conditions of the Creative Commons Attribution (CC BY) license (https:// creativecommons.org/licenses/by/ $4.0 /)$.

\begin{abstract}
Human postmortem specimens are extremely valuable resources for investigating translational hypotheses. Tissue repositories collect clinically assessed specimens from people with and without HIV, including age, viral load, treatments, substance use patterns and cognitive functions. One challenge is the limited number of specimens suitable for transcriptional studies, mainly due to poor RNA quality resulting from long postmortem intervals. We hypothesized that epigenomic signatures would be more stable than RNA for assessing global changes associated with outcomes of interest. We found that H3K27Ac or RNA Polymerase (Pol) were not consistently detected by Chromatin Immunoprecipitation (ChIP), while the enhancer H3K4me3 histone modification was abundant and stable up to the $72 \mathrm{~h}$ postmortem. We tested our ability to use H3K4me3 in human prefrontal cortex from HIV+ individuals meeting criteria for methamphetamine use disorder or not (Meth +/-) which exhibited poor RNA quality and were not suitable for transcriptional profiling. Systems strategies that are typically used in transcriptional metadata were applied to H3K4me3 peaks revealing consistent genomic activity differences in regions where addiction and neuronal synapses pathway genes are represented, including genes of the dopaminergic system, as well as inflammatory pathways. The resulting comparisons mirrored previously observed effects of Meth on suppressing gene expression and provided insights on neurological processes affected by Meth. The results suggested that $\mathrm{H} 3 \mathrm{~K} 4 \mathrm{me} 3$ detection in chromatin may reflect transcriptional patterns, thus providing opportunities for analysis of larger numbers of specimens from cases with substance use and neurological deficits. In conclusion, the detection of H3K4me3 in isolated chromatin can be an alternative to transcriptome strategies to increase the power of association using specimens with long postmortem intervals and low RNA quality.
\end{abstract}

Keywords: postmortem interval; HIV; methamphetamine; brain; H3K4me3

\section{Introduction}

Postmortem human specimens represent an extremely valuable resource with direct translational implications. Tissue repositories collect a great number of brain specimens from HIV-positive $(+)$ and negative individuals, with different viral loads, treatments and ages. Most importantly, specimens may also be from subjects with different substance use disorder patterns and cognitive functions, generating opportunities for identifying important molecular elements tied to recorded clinical and individual variables. Currently, the analysis of the transcriptome can provide in-depth information about pathways, biological processes and even cellular compartments disturbed by variables such as drug abuse. 
Nevertheless, the use of a large fraction of the archived specimens may be limited for determining global transcriptional changes due to problems with RNA quality. Postmortem time interval prior to tissue harvest is one of the main causes of poor RNA quality and presents a challenge to retrieve transcriptional information from a large number of human specimens, particularly the ones from drug users [1-3]. To address this challenge, we investigated whether changes in epigenetic marks such as enhancer histone modifications may be stable surrogates to indicate consequential information about gene transcription patterns, which would otherwise be lost due to poor RNA quality in postmortem specimens. This could enhance the investigation of global changes associated with HIV infection and neurological outcomes, as well as pathways involved in addiction, in a larger number of specimens.

Epigenetic marks associated with transcription include enhancer histone modifications such as H3K4me3 and H3K27Ac in proximal promoters, as well as the presence of RNA Polymerase I/II at transcription starting sites (TSS) [4,5]. These and other epigenetic mechanisms, either enabling or silencing transcription, are highly conserved between eukaryotic species [6-9]. We tested the effect of postmortem intervals on the stability of these epigenetic marks in mouse brain tissue and confirmed that the most stable modification over time was consistently found in human postmortem specimens with poor RNA quality. This information was used to assess signatures in prefrontal cortex specimens from HIV+ subjects that met the criteria of Methamphetamine (Meth) use disorder, or not.

We found that both histone modifications were better preserved than RNA Polymerase and that H3K4me3 was more abundant than H3K27Ac. H3K4me3 was consistently found in postmortem human specimens and allowed the identification of promoter and gene activity in inflammatory and viral response genes, as well as in genes involved in addiction. We conclude that the characterization of the epigenetic landscape can enable the retrieval of useful information from precious specimens with otherwise poor RNA quality, offering an opportunity to expand the analysis of specimens in tissue repositories, such as the National NeuroAIDS Tissue Consortium (NNTC). Importantly, this may help increase the number of analyzed specimens, enhancing sample size and statistical power, while improving models that incorporate common confounders and heterogeneities of the human population to genetic and post-translational patterns.

\section{Materials and Methods}

\subsection{Mouse Postmortem Specimens and ChIP-qPCR}

The studies were performed with the approval of the Institutional Animal Care and Use Committee (IACUC) of the San Diego Biomedical Research Institute (SDBRI). Eighteen 10 weeks old male $\mathrm{C} 57 \mathrm{Bl} / 6$ mice were sacrificed using $5 \%$ isoflurane, and the bodies were maintained at room temperature for $0,6,24,48,72$ and $96 \mathrm{~h}$ prior to dissection and brain harvesting. The brains were divided into two hemispheres, designated for RNA isolation and quality assessment performed as a service by the Microarray Core Facility at The Scripps Research Institute, La Jolla, as well as for chromatin isolation and cross linking. Mouse ChIP-qPCR was performed in isolated chromatin for the detection of H3K4me3, H3K27Ac and RNA Pol II with ChIP-grade antibodies. The reactions were performed in triplicate using $25 \mu \mathrm{g}$ of mouse brain tissue chromatin and $3 \mu \mathrm{L}$ of H3K4me3 antibody (Active Motif, Cat\#39159, Carlsbad, CA, USA), $4 \mu \mathrm{g}$ of H3K27Ac antibody (Active Motif, Cat\#39133) or $4 \mu \mathrm{g}$ of RNA Pol II antibody (Active Motif, Cat\#91151). We performed qPCR using two positive control primers that worked well in similar assays (ACTB, GAPDH), as well as a negative control primer pair that amplifies a region in a gene desert on chromosome 6 (Untr6).

\subsection{Human Postmortem Specimens and ChIP-qPCR}

Frozen human prefrontal cortex brain specimens were provided by the National NeuroAIDS Tissue Consortium (NNTC) upon request and kept at $-80^{\circ} \mathrm{C}$ until experimentation. All experiments were performed with Institutional IBC and IRB approval (IRB18-001-MCM). The prefrontal cortex specimens were selected among all male HIV+ cases 
(receiving ART and exhibiting criteria for global neuropsychological impairment [10-13], with available frozen and paraffin-embedded tissue. The specimens were divided in two groups based on meeting current stimulant abuse/dependence criteria at the last clinical evaluation and urine toxicology positive for methamphetamine (Meth - and Meth,$+ n=3$ case specimens/group). Three fragments of $1 \mathrm{~cm}^{2}$ were separated from each frozen tissue specimen. Half of each fragment was used for RNA extraction and RNA quality assessment performed as a service by the Microarray Core Facility at The Scripps Research Institute, La Jolla. The remaining half was used for simultaneous chromatin isolation and crosslinking. ChIP reactions were performed using $30 \mu \mathrm{g}$ of human HIV+ brain tissue chromatin and $4 \mu \mathrm{g}$ of antibody against RNA Pol II, (Cat\#39097, Active Motif, Carlsbad, CA, USA), H3K27Ac (Cat\#39085, Active Motif) and H3K4me3 (Cat\#39160, Active Motif). Following that, qPCR was performed using two positive control primers (ACTB and GAPDH), as well as a negative control primer pairs that amplify regions in a gene desert on chromosome 12 (Untr12) for human specimens.

\subsection{ChIP-qPCR Statistical Analysis}

Statistical comparisons between postmortem intervals in ChiP-qPCR experiments in mouse and human preparations were performed using ANOVA, followed by Bonferroni's posthoc test, in Prism 8.4.1 (Graphpad Software L.L.C., San Diego, CA, USA). Differences were considered statistically significant at $p<0.05$.

\subsection{RNA Extraction and Quality Assessment}

Mouse and human tissue were homogenized with Kimble Kontes disposable pestles (Sigma-Aldrich, St. Louis, MO, USA), and RNA was extracted using RNAeasy Mini kit (Qiagen, Germantown, MD, USA). RNA quantification was determined by spectrophotometry using a NanoDrop ND-1000 spectrophotometer (NanoDrop Technologies Inc., Wilmington, DE, USA). The OD260/280 ratio was used to evaluate the purity of the nucleic acid samples, and the quality of the extracted total RNA was determined with the Agilent 2100 Bioanalyzer (Santa Clara, CA, USA), at the La Jolla Scripps Research DNA Array Core as a service.

\subsection{Chromatin Preparation}

Minced tissue was washed twice in ice cold PBS and treated with $1 \%$ formaldehyde (Sigma-Aldrich) for $12 \mathrm{~min}$ to crosslink the chromatin, as previously described $[14,15]$. The reaction was stopped with glycine added to a final concentration of $0.125 \mathrm{M}$. The pellets were lysed with lysis buffer containing molecular grade $85 \mathrm{mM} \mathrm{KCl}, 0.5 \% \mathrm{NP} 40$ and $5 \mathrm{mM}$ HEPES pH 8.0) supplemented with a protease inhibitor cocktail, incubated on ice for $15 \mathrm{~min}$ and centrifuged at $3500 \times g$ for $5 \mathrm{~min}$ to pellet the nuclei. The pellet was resuspended in nuclear lysis buffer (10 mM EDTA, 1\% SDS, $50 \mathrm{mM}$ Tris- $\mathrm{HCl}, \mathrm{pH} 8.1)$ at a ratio 1:1 ( $v / w)$, incubated on ice for $10 \mathrm{~min}$ and stored at $-80^{\circ} \mathrm{C}$ until use. The pellets were sonicated, and DNA was sheared to an average length of 300-500 bp. The chromatin extraction was performed using Chromatin IP DNA Purification kit (Active Motif, Carlsbad, CA, USA). Genomic DNA (input) was prepared by treating aliquots of chromatin with RNase, proteinase $\mathrm{K}$ and heat $\left(65^{\circ} \mathrm{C}\right)$ to reverse cross-linking, followed by phenol and chloroform extractions and ethanol precipitation. Pellets were resuspended in $10 \mathrm{mM}$ Tris, $1 \mathrm{mM}$ EDTA, and the resulting DNA was quantified on a Nanodrop spectrophotometer (Thermo Fisher Scientific, Chicago, IL, USA). Results were used to calculate the total yield.

\subsection{ChIP-Seq}

ChIP was performed using the ChIP-IT High Sensitivity Kit (Active Motif). ChIP-seq reactions were carried out with 30 ug of chromatin and anti-H3K4me3 antibody. The ChIP DNA was processed into an Illumina ChIP-Seq library and sequenced to generate reads, which were aligned to the $\mathrm{H}$. sapiens genome annotation (Hg38 assembly) and unique aligns (removed duplicates) were obtained. A signal map showing fragment densities 
along the genome was visualized in the Integrated Genome Browser (IGB) and MACS peak finding was used to identify peaks. Control data was derived from positive and negative control alignments. The 75-nt sequence reads generated by Illumina sequencing (using NextSeq 500) were mapped to the genome using the BWA algorithm with default settings. Alignment information for each read was stored in the BAM format. Only reads that passed Illumina's purity filter, aligned with no more than 2 mismatches and mapped uniquely to the genome were used in the subsequent analysis. In addition, duplicate reads were removed. Since the $5^{\prime}$-ends of the aligned reads represent the end of ChIP/IP-fragments, the tags were extended in silico using Active Motif software at their 3 '-ends to a length of 150-250 bp, depending on the average fragment length in the selected $200 \mathrm{bp}$ library size. To identify the density of fragments along the genome, the genome was divided into 32-nt bins and the number of fragments in each bin was determined. This information in bigWig was visualized in UCSC genome browser. Intervals with tag enrichment were identified by chromosome number, start and end coordinates using MACS [16] and SICER [17], corresponding to significant enrichments in the ChIP/IP data compared to random Input. For normalization, the tag number of all samples was reduced by random sampling to the number of tags present in the smallest sample, using default settings. To compare peak metrics, overlapping Intervals were grouped into merged regions, defined by the start coordinate of the most upstream Interval and the end coordinate of the most downstream Interval. In locations where only one sample had an Interval, this defined the merged region. After defining the Intervals and Merged Regions, their genomic locations along with their proximities to gene annotations and other genomic features were determined and presented in .xls spreadsheets.

\subsection{ChIP Analysis}

Genes with $\mathrm{H} 3 \mathrm{~K} 4 \mathrm{me} 3$ peaks found within $10 \mathrm{~kb}$ of start/end were compared in the ChIP samples. Overlap between the samples was high (70-90\% in pairwise comparisons). Active region identification settings were -7500 to 2500 from promoter start, with 10,000 upstream and downstream-margin. The comparison of all samples averaged by group and the peak metrics obtained in Bioconductor ChiPpeakAnno (www.bioconductor.org, 2020) [18] were used in combination with a present/absent peak call information to find genomic regions with H3K4me3 occupancy patterns. Sequencing statistics can be seen in Table 1. The average fragment densities for 28,826 human genes (from TSS to termination site) and the corresponding promoters (from -1000 to $+1000 \mathrm{nt}$ relative to TSS) were determined. Peak values in gene bodies were corrected by length. For the analysis, the data files were normalized to the same number of unique alignments without duplicate reads. Intervals were determined using the SICER algorithm at a cutoff of FDR1E-10 and a Gap parameter of $600 \mathrm{bp}$ (which merges peaks located within $600 \mathrm{bp}$ of each other). Gene intervals (peaks) were determined using the SICER algorithm at a cutoff of FDR1E-10 and a Gap parameter of $600 \mathrm{bp}$ (which merges peaks located within $600 \mathrm{bp}$ of each other into a single "island"). The overlap between the samples was high (70-90\% in pairwise comparisons). The tag densities/signal metrics relative to known gene annotations were examined and used in systems analysis.

Table 1. Sequencing statistics by group.

\begin{tabular}{cccc}
\hline & $\begin{array}{c}\text { Average HIV+Meth- } \\
\text { H3K4me3 }\end{array}$ & $\begin{array}{c}\text { Average HIV+Meth+ } \\
\text { H3K4me3 }\end{array}$ & $\begin{array}{c}\text { Pooled Input } \\
\text { hg38 }\end{array}$ \\
\hline Total number of reads & $39,365,646$ & $40,840,923$ & $42,982,011$ \\
\hline $\begin{array}{c}\text { Total number of } \\
\text { alignments (hg38) }\end{array}$ & $35,790,215$ & $38,438,156$ & $39,813,903$ \\
\hline Unique alignments (-q 25) & $33,267,427$ & $35,878,237$ & $34,930,380$ \\
\hline $\begin{array}{c}\text { Unique alignments } \\
\text { (without duplicates) }\end{array}$ & $23,200,850$ & $26,581,519$ & $32,071,577$ \\
\hline
\end{tabular}




\subsection{Systems Analysis}

Ratio and $\log 2$-fold-change were calculated using tag densities/signal metrics relative to known gene annotations to group average signal values, with a cut off $>$ and $<1.5$-fold, and $p<0.05$ in pairwise comparisons performed in licensed JMP Pro 12 software (SAS Institute Inc., Cary, NC, USA). Enrichment, processes and pathway annotations were performed using z scores by licensed Ingenuity Pathway Analysis software (IPA, Qiagen), confirmed by DAVID Bioinformatics Resources 6.8 (https: / / david.ncifcrf.gov, 2020) and then visualized using local search features in GeneMANIA plugin [19-21] (www.genemania.org) in Cytoscape 3.7.0 platform [22] (www.cytoscape.org, 2020) with Homo sapiens sources from Reactome [23] (www.reactome.org, 2020) and BioGRID_ORGANISM [24-26] (https: / / thebiogrid.org, 2020). Transcription factor-DNA interactions derived from merged peak regions were modeled using licensed TRANSFAC v2021.1 [27-29] (GeneXplain GmbH, Wolfenbuttel, Germany) with JASPAR 2020 position frequency matrix [30] and input provided in .BED format, restricted to $H$. sapiens nervous system.

\subsection{In Situ Hybridization for HIV (vRNA) Detection}

Paraffin-embedded sections of prefrontal cortex (from the same subjects) were provided by the NNTC upon request. RNAScope $2.5 \mathrm{HD}$ assay (Advanced Cell Diagnostics, ACD) was performed. Briefly, pre-treatment was performed with RNAscope $2.5 \mathrm{HD}$ Detection Kit (RED) (Cat\# 322360), RNAscope 2.5 Pretreat Reagents-H202 and Protease Plus (Cat\#322330), RNAscope Target Retrieval (Cat\#322000) and RNAscope Wash Buffer (Cat\#310091), following manual instructions. Probe set V-HIV1-clade B-C3 (Cat\#425531C3) targeting different segments within the gag-pol region, as described [31-33]. Images were captured using the light feature of a Zeiss AXIO Observer.Z1 (Carl Zeiss AG, Oberkochen, Germany).

\section{Results}

Peaks of enrichment in ChIP-seq data may suggest stable and predictive standards associated with transcription, especially the ones in promoter regions [5]. We selected 3 epigenetic marks associated with active transcriptional patterns: H3K27Ac, H3K4me3 and RNA Polymerase II (Pol). The stability of different epigenetic marks was tested in postmortem mouse specimens. Preservation of the most stable was confirmed in human postmortem brain specimens with low RNA quality and used to compare prefrontal cortex signatures of Meth use disorder in the context of HIV infection.

\subsection{Stability of Enhancer Epigenetic Marks in Mouse Postmortem Brains Overtime}

The stability of H3K27Ac, H3K4me3 and RNA Pol was tested in mouse brains, at different postmortem intervals, from 0 to $96 \mathrm{~h}$ time points. For that, $\mathrm{C} 57 \mathrm{Bl} / 6$ mice were sacrificed and left at room temperature in groups of 3, for $6 \mathrm{~h}, 24,48,72$ and $96 \mathrm{~h}$ before dissection and brain harvesting. Figure 1 shows representative RNA electrophoresis indicating bands and increasing fragmentation over higher postmortem time intervals. The 2 histogram peaks in $x$-axis designate the $18 \mathrm{~s}$ and $28 \mathrm{~s}$ ribosomal RNA, respectively. The $y$-axis indicates fragment units (FU) derived from band density in relation to standards. Notice that fragment units decrease by about $50 \%$ at $24 \mathrm{~h}$ compared to 0 and $6 \mathrm{~h}$, although $18 \mathrm{~s}$ and $28 \mathrm{~s}$ peaks in histograms may retain aspects of integrity. At $0-6 \mathrm{~h}$, RIN was $8.8 \pm 0.5$. From $24 \mathrm{~h}$ on, RIN was consistently $<7.2$, reaching $2.5 \pm 0.3$ at $96 \mathrm{~h}$. RIN $<7.5$ is considered unfit for RNA studies, as it signifies a significant fragmentation, indicating poor quality that results in inaccurate transcriptional data. 
A)

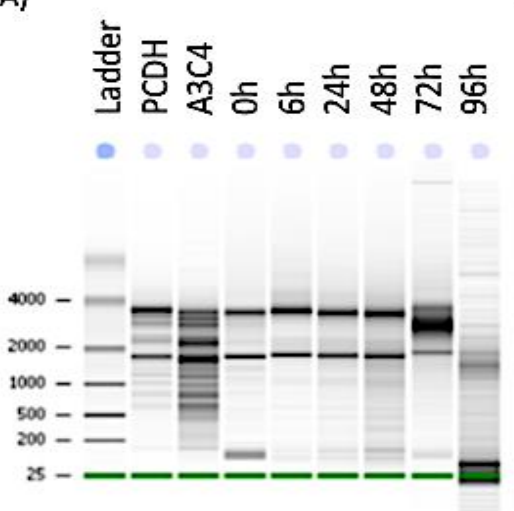

B)
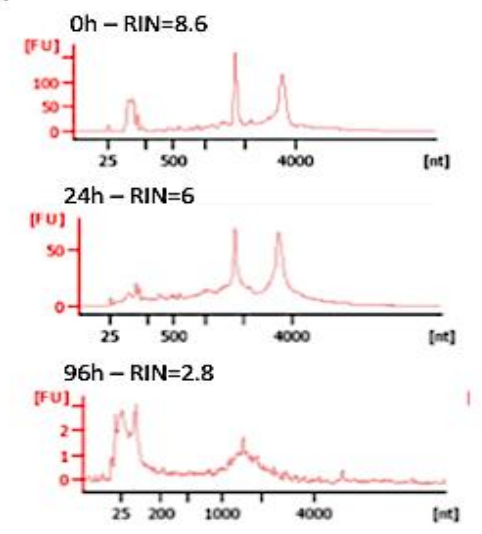

Figure 1. RNA stability in mouse brains. $\mathrm{C} 57 \mathrm{Bl} / 6$ mice were sacrificed and left at room temperature for $0,6,24,48,72$ or $96 \mathrm{~h}$ before dissection ( $\mathrm{n}=3$ /interval). PCDH and A3C4 are Agilent RNA integrity reference standards. Their brains were harvested, and half was snap frozen for RNA extraction. The RNA quality was tested by (A) gel electrophoresis, in an Agilent Bioanalyzer 2100. (B) RNA integrity numbers (RIN) were derived from $18 \mathrm{~s}$ and $28 \mathrm{~s}$ fragment units (FU) in experimental specimens and reference standards, as shown in 0,24 and $96 \mathrm{~h}$ representative histograms. RIN $<7.5$ is considered unfit for RNA studies, as it indicates a significant fragmentation.

We used these mouse brain specimens to test the interaction between functional genomic marks in mouse brains and time in different postmortem intervals. For that, we used ChIP-qPCR to test H3K4me3, H3K27Ac and RNA Pol II onto promoters of two primer-amplified positive control genomic regions, corresponding to the housekeeping genes beta actin (ACTB) and glyceraldehyde-3-phosphate dehydrogenase (GAPDH), which are permanent and constitutively transcribed with a fixed number of occupancy units across samples, as well as a negative control primer pair that amplifies a region in a gene desert on chromosome 6 (Untr6), as recommended by standard quality control protocols [34]. Figure 2 shows the relative increment of H3K4me3, H3K27Ac and RNA Pol II binding events in the amplified ACTB and GAPDH genes compared to Untr6 negative control genomic region. RNA Pol became undetectable faster than H3K27Ac and H3K4me3, indicating less stability. Both histone modifications had a decrease at $24 \mathrm{~h}$, were similar between 24 and $72 \mathrm{~h}$ and suffered a drastic loss at $96 \mathrm{~h}$. H3K4me3 was the modification with stronger signal over input, as shown in the increase of 200-fold above input at the GAPDH gene. This indicates that H3K4me3 may have a better detection stability up to $72 \mathrm{~h}$ of postmortem interval.

\subsection{Stability of Functional Genomic Marks in Human Postmortem Prefrontal Cortex Specimens} with $R I N<7.2$

We hypothesized that H3K4me3 would be consistently detected in human specimens with poor RNA quality not considered adequate for transcriptional studies. We tested the same marks, H3K4me3, H3K27Ac and RNA Pol, in human postmortem prefrontal cortex specimens, which had a poor RNA quality $(\mathrm{RIN}<6.2)$ and were not considered adequate for transcriptional studies. The specimens were obtained from the NNTC and were from ART-treated male subjects from the UCLA cohort between 2003 and 2011, following inclusion criteria described in methods. Table 2 shows subject characteristics that were relevant for grouping. 


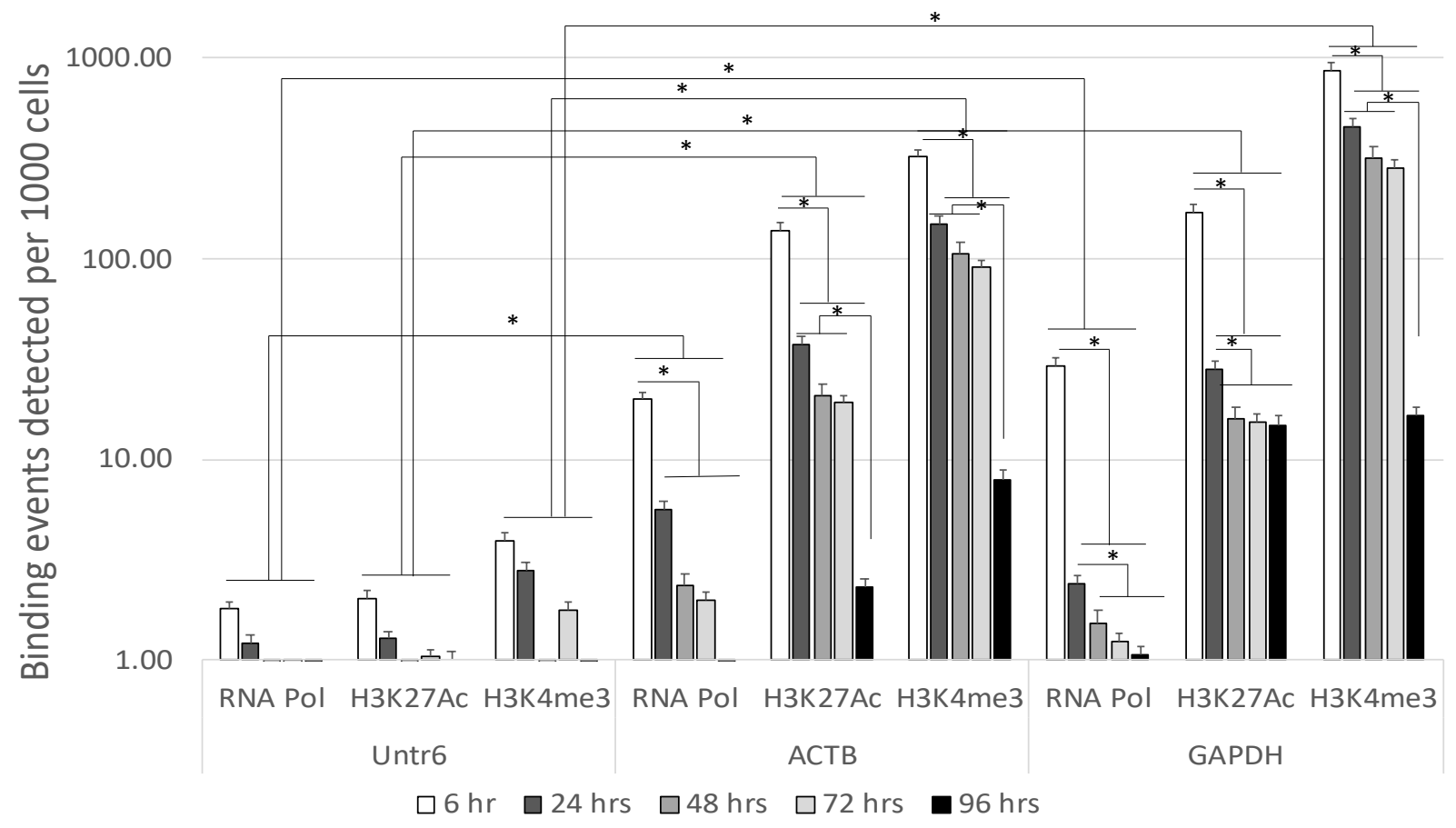

Figure 2. Postmortem stability of genomic epigenetic marks positively associated with transcription. Mice were sacrificed and maintained at room temperature for $6,24,48,72$ and $96 \mathrm{~h}$ prior to the dissection and brain harvesting. ChiP-qPCR was performed in isolated chromatin for the detection of H3K4me3, H3K27Ac and RNA Pol II with ChIP-grade antibodies. The reactions were performed in triplicate using $25 \mu \mathrm{g}$ of mouse brain tissue chromatin and $3 \mu \mathrm{L}$ of H3K4me3 antibody (Active Motif, Cat\#39159), $4 \mu \mathrm{g}$ of H3K27Ac antibody (Active Motif, Cat\#39133) or $4 \mu \mathrm{g}$ of RNA Pol II antibody (Active Motif, Cat\#91151). We performed qPCR using two positive control primers that worked well in similar assays (ACTB, GAPDH), as well as a negative control primer pair that amplifies a region in a gene desert on chromosome 6 (Untr6). ${ }^{*} p<0.05$ in comparisons indicated by lines.

Table 2. Specimen subject groups, viral load at CD4 nadir, ART prescribed at any given time and RNA integrity number (RIN) following extraction.

\begin{tabular}{ccccc}
\hline Group & Case\# & Plasma VL at CD4 nadir & ART History & Frontal Cortex RNA RIN \\
\hline HIV+Meth- & 4067 & 5.12 & ZDV + 3TC, LPV + RTV, TFV & 6.6 \\
HIV+Meth- & 4077 & 2.6 & ATV, FTC, RTV, TFV, TFV + FTC & 5.7 \\
HIV+Meth- & 4083 & 3.35 & ZDV + 3TC, RFV, ATV, RTV, TFV / FTC & 6.8 \\
HIV+Meth+ & 1163 & 5.57 & DRV, RTV, TFV + FTC & 4.6 \\
HIV+Meth+ & 2074 & 4.57 & 3TC, D4T, IDV, NVP, RTV, ABC, & 5.2 \\
HIV+Meth+ & 4167 & 6.28 & LPV + RTV, NFV, DDI, TFV & 6.3 \\
\hline
\end{tabular}

Legend: ART-Abbreviations: ZDV—zidovudine; 3TC-lamivudine; LPV—lopinavir; ATV—atazanavir; FTC—emtriditabine; RTV—ritonavir; TFV—-tenofovir; DRV—darunavir; D4T—stavudine; IDV—indinavir; NVP—nevirapine; ABV—abacavir; NFV—nelfinavir; DDI-didanosine.

Detection of viral RNA in matching paraffin embedded tissue sections by RNAscope was detectable, although not consistently in all the specimens (Figure 3). Viral DNA was not identified.

Figure 4 shows that a stronger increase over input was observed in both histone modifications compared to RNA Pol, with better results for H3K4me3. Like in mice, H3K4me3 had a 200-fold increase in signal over input at the GAPDH gene, indicating cross-species consistency. 

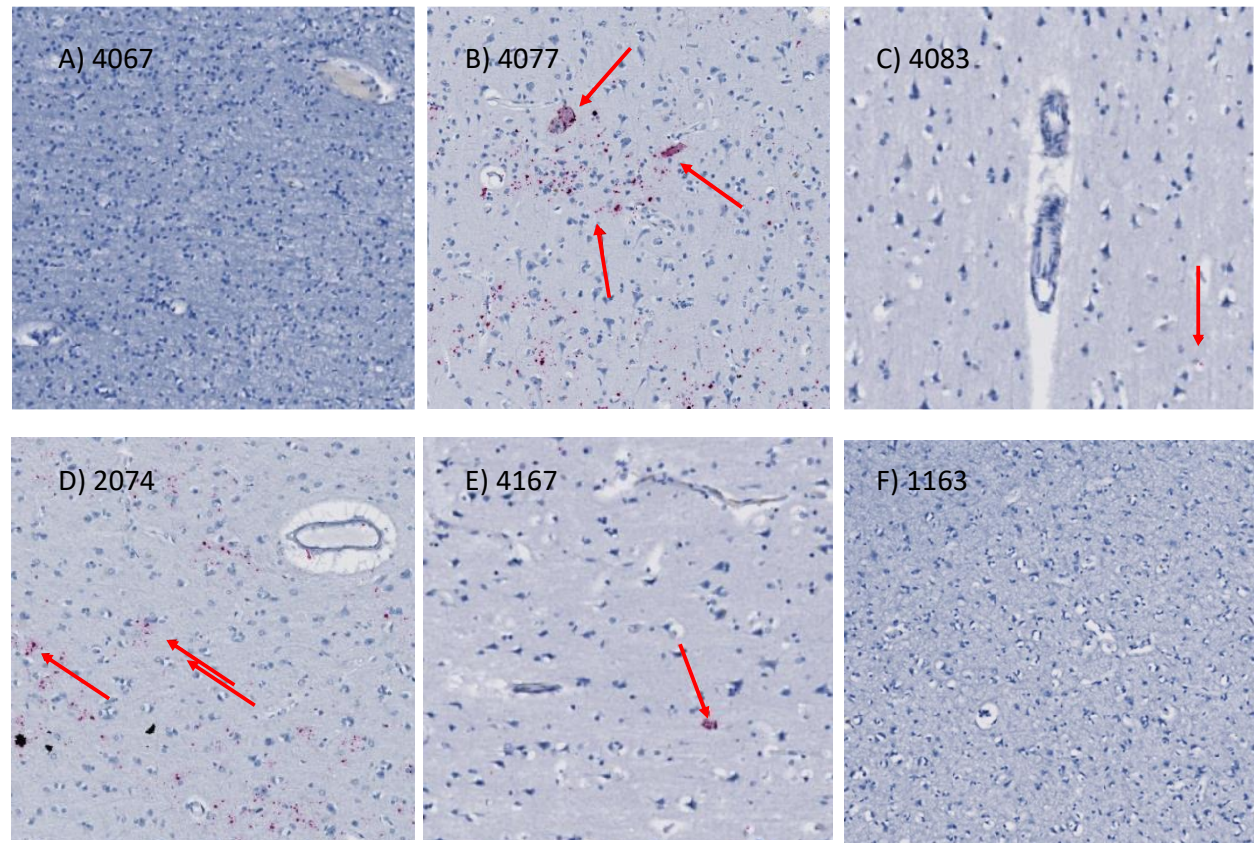

Figure 3. RNA scope in situ hybridization showing HIV-infected cells in prefrontal cortex. HIV vRNA probes were used to detect active virus. Representative sections from the prefrontal cortex are shown for specimens (A) 4067, (B) 4077, (C) 4083, (D) 2074, (E) 4167 and (F) 1163. Red arrows show examples of positive staining patterns in pink, which correspond to expression of HIV vRNA in the brain parenchyma. Magnification 60X.

\subsection{Quality Controls in Genome-Wide Peak Data Confirms H3K4me3 Stability in Postmortem Human Specimens}

Given the relative stability of H3K4me3 in mouse and human specimens, this genomic unit was then selected for comparing two groups of HIV+ brain specimens represented by 6 cases with HIV-associated neurological diagnosis, divided in 2 subgroups, being 3 cases with no history of substance use and 3 cases that fit Meth-use criteria, based on self-reported recent and life-time use. Table 1 shows the patient characteristics associated with the specimens used in signature comparisons. All unidentified subjects were 20-40-year-old males. Viral load at CD4 nadir, ART information and observations from available neuropsychological (NP) testing are shown in Table 1. Prefrontal cortex specimens from these subjects had RIN values below 7.2. These were used to test the hypothesis that epigenetic marks are sufficiently stable to provide information from specimens that would otherwise have a limited value for the study of global changes.

The results in Figure 4A suggest that H3K4me3 signal is stronger than H3K27Ac, although both are stable in postmortem specimens up to $72 \mathrm{~h}$ postmortem. Figure $4 \mathrm{~B}$ shows H3K4me3 peaks in representative specimens, at the GAPDH gene.

The quality of genome-wide H3K4me3 signal across samples was tested using different methods (Figure 5). Active regions were merged within and between groups, revealing that specimens in both groups were stable regarding location of peaks relative to genomic coordinates and annotations mapped to the Human Hg38 assembly and visualized in pie charts (Figure 5A). Tag distribution occurred predominantly in proximal promoters and introns, indicating that genomic activity was likely to be associated with transcriptional events, but also in regulatory regions, as opposed to $\mathrm{Hg} 38$ random controls in introns and non-coding regions (Figure 5A). Differences in peak intensity have identified mutual as well as exclusive signatures, indicating that this strategy can distinguish between groups (Figure 5B). For instance, 8525 active genomic regions were identified in HIV+Meth- specimens, which were not present in Meth users. Conversely, HIV+Meth+ specimens presented 7857 exclusive active regions. The majority of the active genomic regions were shared by specimens in both groups. The number of active regions per chromosome was also similar 
across cases and between groups (Figure 5C), with large activity in chromosomes 1 and 19 and comparatively low activity in chromosomes 18, 21 and $\mathrm{Y}$.

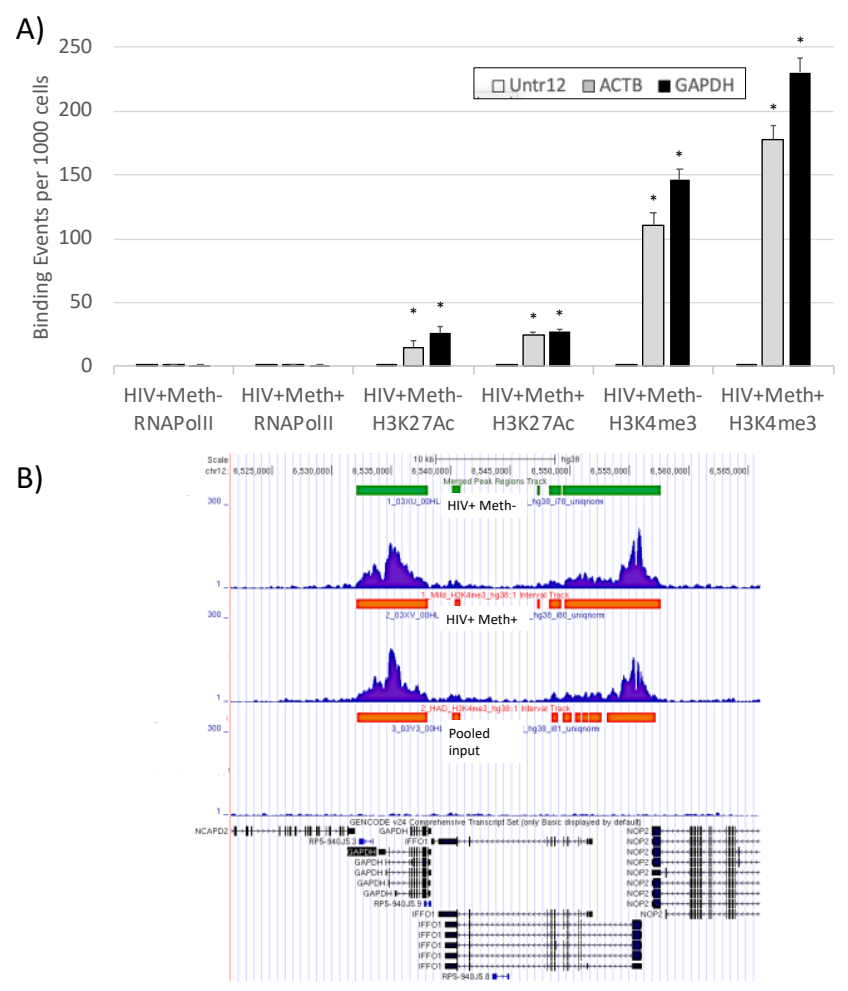

Figure 4. Comparison of detectable epigenetic marks in HIV+ prefrontal cortex specimens. Using ChIP-qPCR, we tested our ability to detected genomic marks in postmortem human prefrontal cortex tissue with low RNA quality. (A) RNAPol, H3K27Ac and H3K4me3 were detected in 3 amplified genomic regions: A desert sequence in the human chromosome 12 was used as negative control (white bars), ACTB (gray bars) and GAPDH (black bars) promoters. ${ }^{*} p<0.05$ compared to Untr12 negative control. (B) H3K4me3 peaks in the GAPDH genomic sequence in representative postmortem specimens from both groups. ${ }^{*} p<0.05$ in comparisons indicated by lines.

Figure 6 shows the H3K4me3 peak distribution patterns in both groups of specimens, both in average plots and heatmaps from tag distributions across target regions such as gene bodies for all target regions (Figure 6A,D), mapping merged regions for all peak regions (Figure $6 \mathrm{~B}, \mathrm{E}$ ), and transcription start site (TSS, at $0 \mathrm{bp}$ ) proximal promoters (Figure $6 \mathrm{C}, \mathrm{F}$ ). The heatmaps (values in $z$-axis/color, regions in $y$-axis) are used for visualization of read densities or H3K4me3 tag distributions (using bigWIG metrics), which are mapped across target regions. Peaks mapped to gene bodies located between $-2 \mathrm{~kb}$ and $+2 \mathrm{~kb}$, excluding distal downstream and upstream peak signals (Figure 6D). Merged Regions correspond to all peak regions from $-5 \mathrm{~kb}$ to $+5 \mathrm{~kb}$ to include distal promoter and regulatory regions (Figure 6E). Peaks in proximal Promoters were located near the TSS, between $-1.5 \mathrm{~kb}$ and $+1.5 \mathrm{~kb}$ (Figure $6 \mathrm{~F}$ ). These heat maps show H3K4me3 distribution patterns that characterize different genes and active genomic regions. The heatmaps were clustered into 5 groups based on where tags were located within the gene sequence, using default settings. The clusters $\mathrm{C} 1-\mathrm{C} 5$ differed between gene body, merged and promoter heatmaps, due to the cut-off distance from the TSS used to build each one of them. These patterns are not expected to differ at least drastically between groups, in spite of the differences in Meth use, which might be detected rather by a granular analysis of peak intensities. Thus, the comparison between HIV+Meth- and HIV+Meth+ in Figure 6 suggests that specimens in both groups followed similar and normal pattern distributions with parallel clusters, indicating no aberrant antibody binding and signal above pooled input controls, adding up to build confidence on data quality. The comparison can be also established and visualized 
as average plots (Figure 6A-C), which average the values for all target regions in heatmaps into histograms and indicate tag distribution in reference to the TSS in $x$-axis. Consistency across specimens was further confirmed from a pairwise comparison of the averaged tag numbers for merged regions in the HIV+Meth- and HIV+Meth+ groups; a scatter plot was produced with a Pearson correlation coefficient $=0.958$ and a slope $=0.977$.

A)

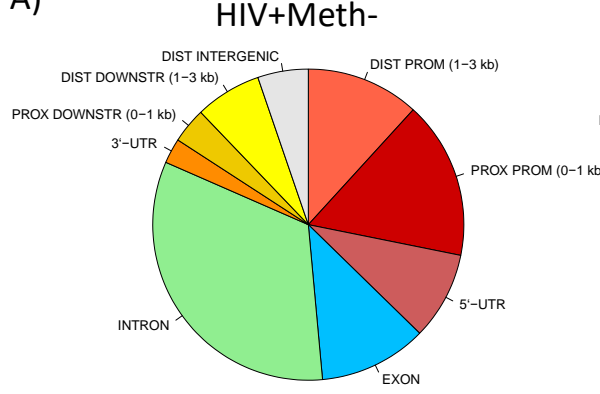

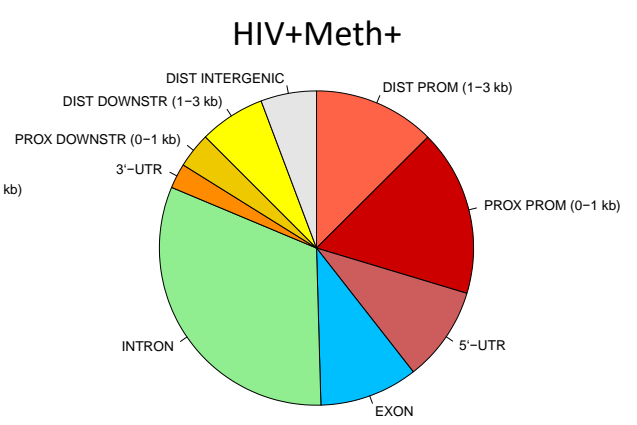

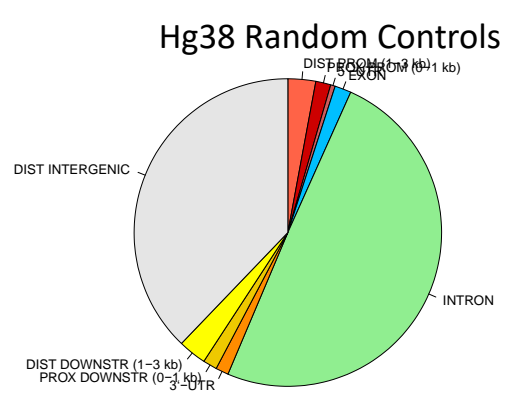

B)

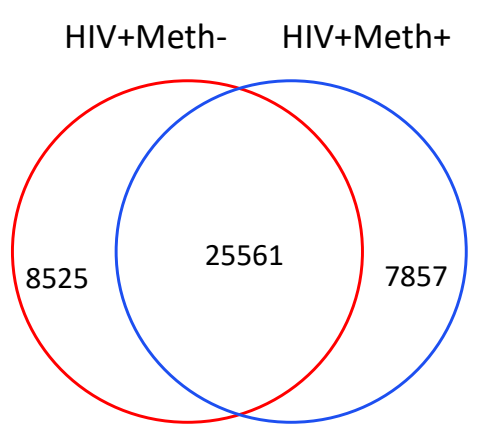

C)

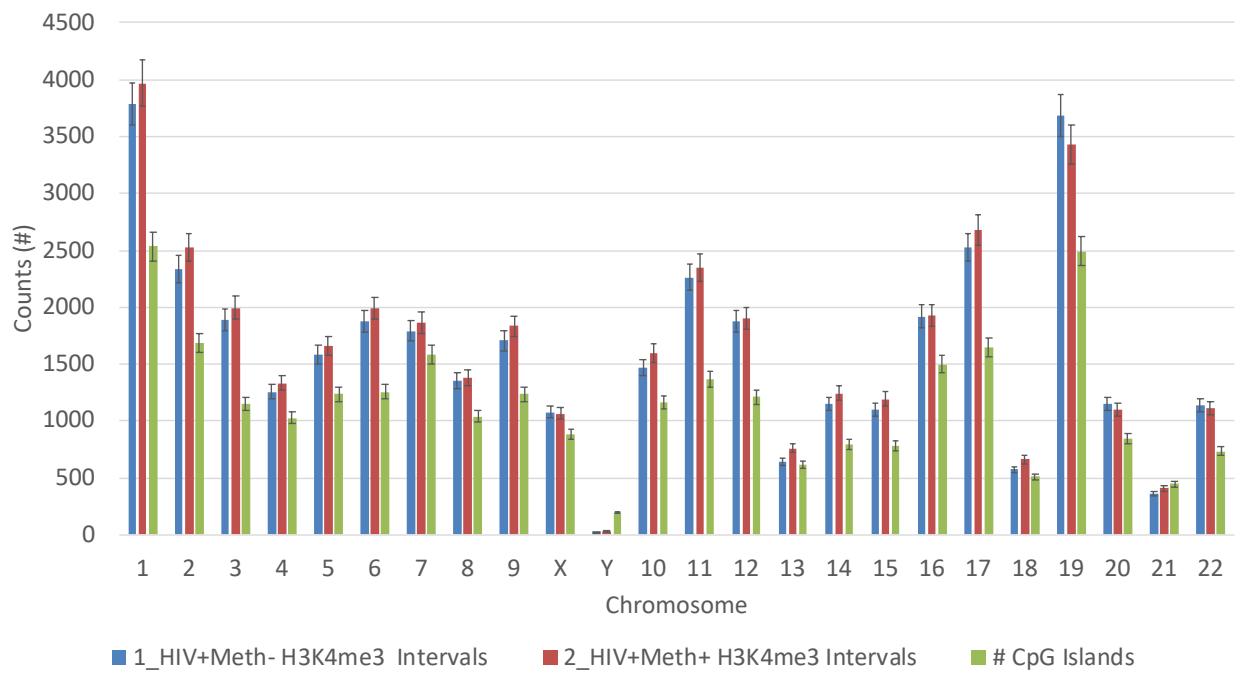

Figure 5. Mapping of HeK4me3 active genomic regions in human postmortem brain specimens. (A) Pie charts showing the distribution of $\mathrm{H} 3 \mathrm{~K} 4 \mathrm{me} 3$ in gene sequences in both groups, with genome wide frequency of modifications within introns, exons, $5^{\prime}$-UTR, proximal $(0-1 \mathrm{~kb})$ and distal $(1-3 \mathrm{~kb})$ promoters, distal intergenic promoter regions, proximal $(0-1 \mathrm{~kb})$ and distal (1-3 kb) downstream regulatory regions and $3^{\prime}$-UTR. As a control, randomly located peaks were also ran against the same genomic features database using the entire interval region aligned to the Human $\mathrm{Hg} 38$ genome assembly. (B) Venn's diagram showing genome wide exclusive and mutual merged active regions in HIV+Meth- and HIV+Meth+ cases ( $\mathrm{n}=3$ /group). (C) Number of HeK4me3 active peak intervals and CpG islands per chromosome in averaged HIV+Methand HIV+ Meth+ cases. 
A)

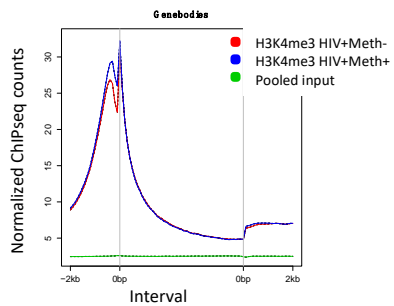

D)

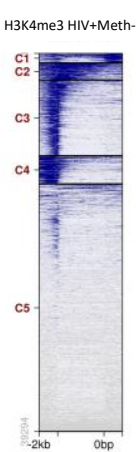

ChIPseq counts
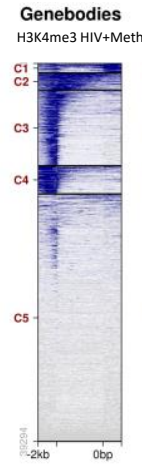

Interval

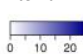

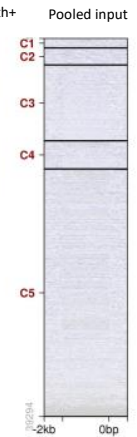

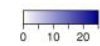

B)

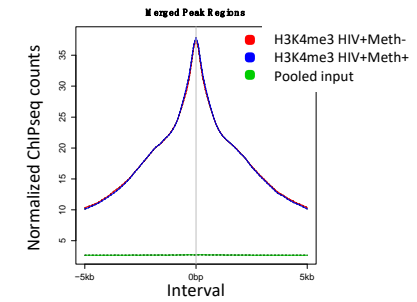

E)

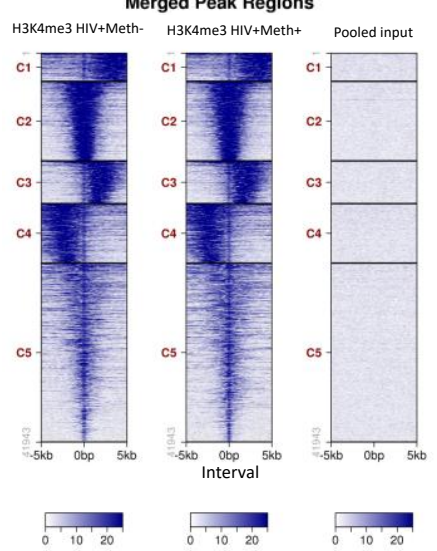

C)

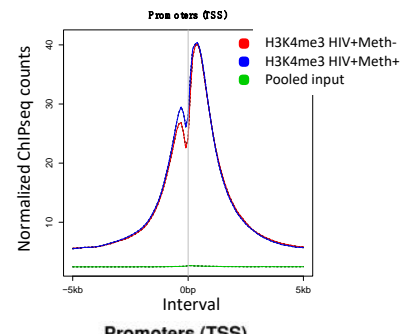

F)

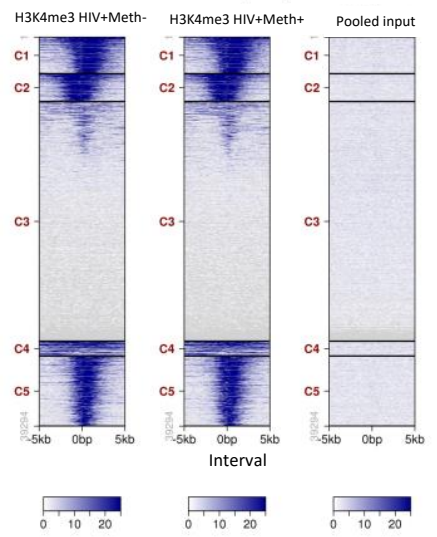

Figure 6. Average plots and heatmaps. Average plots and heatmaps were produced from aggregated peak scores indicating tag distributions (using bigWIG metrics) across target regions identified as (A,D) gene bodies (+/ - $2 \mathrm{~kb}),(\mathbf{B}, \mathbf{E}) \mathrm{Merged}$ Regions $(+/-5 \mathrm{~kb})$ and $(\mathbf{C}, \mathbf{F})$ proximal to transcription start site (TSS) promoter regions $(+/-1.5 \mathrm{~kb})$. (A-C) Average plots correspond to histograms of the average distribution of all regions. (D-F) Values in heatmaps are represented in z-axis/color and regions in $y$-axis, using a 5-cluster default, indicated by $\mathrm{C} 1-\mathrm{C} 5$ in $y$-axis for each region of interest. The gradient blue-to-white color indicates high-to-low count in the corresponding interval region.

\subsection{H3K4me3 Can Provide Insights into Biological Processes and Pathway Usage in Specimens with Limited Value in Global Transcriptome Studies}

We used H3K4me3 to test our ability to use epigenomics as an alternative to transcriptome strategies and increase power in archived human tissues. Peak values were averaged, and fold change between HIV+Meth- and HIV+Meth+ groups was calculated. The strong signal of H3K4me3 and differences between groups were detectable, as exemplified in Figure 7 , showing a representative randomly selected genomic region associated with the AATK (Apoptosis-associated tyrosine kinase) gene sequence in chromosome 17. A representative specimen from the HIV+Meth+ group showed a higher H3K4me3 peak in the proximal promoter region compared to a representative HIV+Meth- specimen, indicating that promoter activity is higher for this gene in the context of Meth, suggesting it is more likely to be transcribed in drug users, while activity within the intron did not differ between the specimens.

The application of a systems biology approach via Genemania and IPA has suggested that this strategy is able to provide important information on functional processes and pathway usage, while mapping effects of infection and co-morbidities on functional units of the genome. Overall, we found 6062 active intervals located upstream the gene sequence, of which 2210 were within proximal promoter regions $(-1 \mathrm{~kb}-0)$ (Figure 6F, C2). Of these, 1540 showed a high degree of connectivity based on pathway and physical interactions, a large fraction of them with detectable changes in peak intensity between specimens of the two groups (Figure 8). An approach limited to genes containing H3Kme3 in proximal promoters produced significant annotations in OMIM_DISEASE that include somatic cancer $(p=0.0003)$ and susceptibility to obesity $(p=0.006)$. Overrepresented functional annotations are within phosphoproteins $\left(p=5.3 \times 10^{-103}\right)$, alternative splicing $\left(p=5.8 \times 10^{-31}\right)$ and ubiquitin conjugation $\left(p=4.7 \times 10^{-28}\right)$. Biological processes (GOTERM) include positive regulation of GTPase activity $\left(p=6.8 \times 10^{-10}\right)$, Regulation of transcription 
$\left(p=3.2 \times 10^{-9}\right)$, Wnt signaling pathway $\left(p=1.8 \times 10^{-8}\right)$, Cell migration $\left(p=2.4 \times 10^{-7}\right)$, MAPK cascade $\left(p=1.7 \times 10^{-7}\right)$, neuron projection development $\left(p=3.0 \times 10^{-6}\right)$, positive regulation of apoptosis $\left(p=4.3 \times 10^{-6}\right)$, oxidative response $\left(p=6.8 \times 10^{-5}\right)$ and glial cell differentiation $\left(p=6.6 \times 10^{-4}\right)$. Pathway annotations (KEGG) for genes with proximal promoter epigenetic activity are Pathways in cancer $\left(p=2.5 \times 10^{-16}\right)$, several pathways involved in neurotransmitter signaling and neurological pathogenesis, such as cholinergic synapse $\left(p=1.5 \times 10^{-7}\right)$, oxytocin signaling $\left(p=6.8 \times 10^{-7}\right)$, glutamatergic synapse $\left(p=9.4 \times 10^{-7}\right)$, dopaminergic synapse $\left(p=3.9 \times 10^{-6}\right)$, cAMP signaling $\left(p=5.6 \times 10^{-5}\right)$, amphetamine addiction $\left(p=1.2 \times 10^{-5}\right)$, serotoninergic synapse $\left(p=9.4 \times 10^{-4}\right)$, morphine addiction $\left(2.7 \times 10^{-3}\right)$ and endocannabinoid signaling $\left(p=2.5 \times 10^{-3}\right)$. Inflammatory and chemokine pathways were also identified $\left(p=1.4 \times 10^{-5}\right)$. This indicates that epigenetic strategies like this can distinguish disruptions in neurotransmitter signaling.

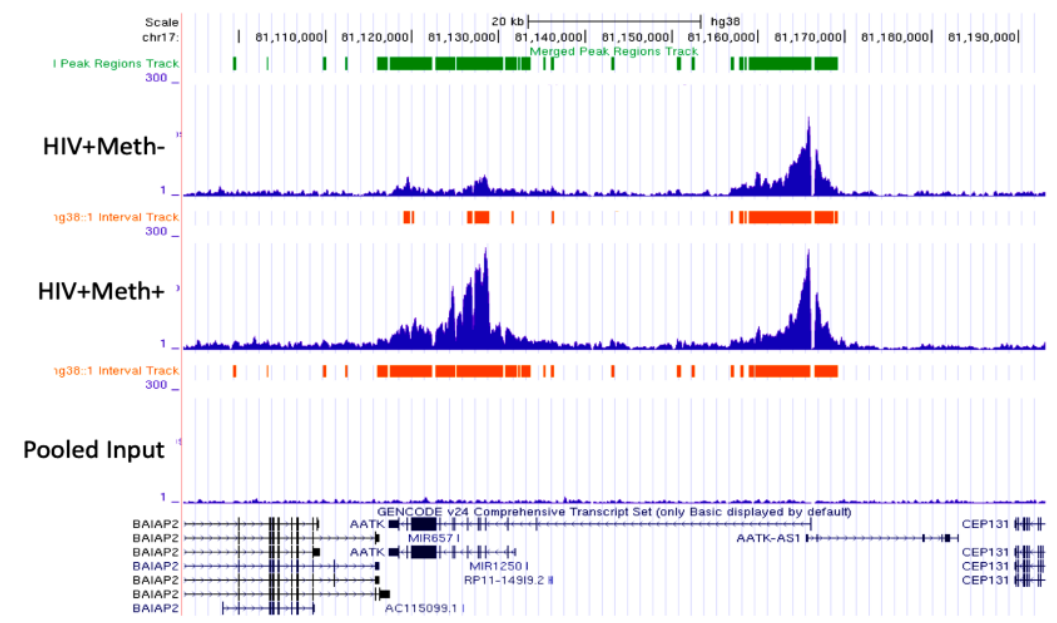

Figure 7. Example of detectable H3K4me3 tag differences between HIV+Meth- and HIV+Meth+ specimens. AATK Gene (apoptosis-associated tyrosine kinase), with similar marks in the gene regulatory region, but enhanced at the promoter in a HIV+Meth+ representative specimen. Visualized using Integrated Genome Browser.

We have identified 2210 genes with active proximal promoter, with both increased (orange shades) and decreased (blue shades) promoter activity associated with Meth use and white nodes corresponding to no change (Figure 8). In Figure 8, it is important to notice the high degree of connectivity between the genes that have H3K4me3 activity, indicating that genomic activity is an orchestrated phenomenon. Nevertheless, many genes with significant proximal promoter activity did not show functional or physical interactions with each other and remained independent. A complete list of these genes and fold changes between groups is available in Supplementary Materials.

The genes in Figure 8 were further filtered based on a significant $+/-1.5$-fold change cut off in a comparison between HIV+Meth- and HIV+Meth+. Tight clustering criteria produced two high score nodes, calculated in Cytoscape default network topology statistics settings, based on the number of neighboring nodes and the number of connected pairs between all neighbors. The first, a 5.2 score node, indicates a cluster where each gene represented by node circles have an average of 5.2 related neighboring genes and with interdependent functional domains based on genomic (pink edge connectors), physical (red) and pathway interactions (green connectors) (Figure 9A). The genomic regions annotated to genes in this cluster exhibited both increased (orange nodes) and decreased (blue nodes) promoter activity, or no change (white nodes) in correlation with Meth use (Figure 9A). In order to further visualize the potential implications of those changes and relationships between these genes, we performed a functional annotation cluster analysis (Figure 9B), which identified biological processes as well as transcription regulators (Figure 9B). For instance, increased promoter activity associated with Meth included genes annotated 
to acute inflammation, macrophage infiltration, cell movement of antigen presenting cells as well as necrosis, apoptosis, and cell death of muscle cells. These changes were predicted as being orchestrated by IFNG, which showed a significant 2.3-fold increase in its promoter genomic activity $(p<0.0001)$. Other IFN pathway components such as IRF1 (1.8-fold, $p<0.0001)$ or transcriptional regulators JUN (1.8-fold, $p<0.001)$ and SOX2 (1.8-fold, $p<0.001)$ were also identified as key components that showed significant changes in the context of Meth (Figure 9B). Overall, this suggests that the inflammatory process is enhanced in HIV+Meth users, in an IFN-dependent manner. Interestingly, genes with decreased promoter activity (shades of blue) shared connections with genes with increased promoter activity, based on physical protein-protein and genetic interactions, as well as shared domains or pathway, as shown in Figure 9A, indicating potential regulators. Neurological pathways involved memory and cognition, as well as CREB signaling in neurons (Figure 9B) were identified. In Figure 9B, edges or connectors are directional.

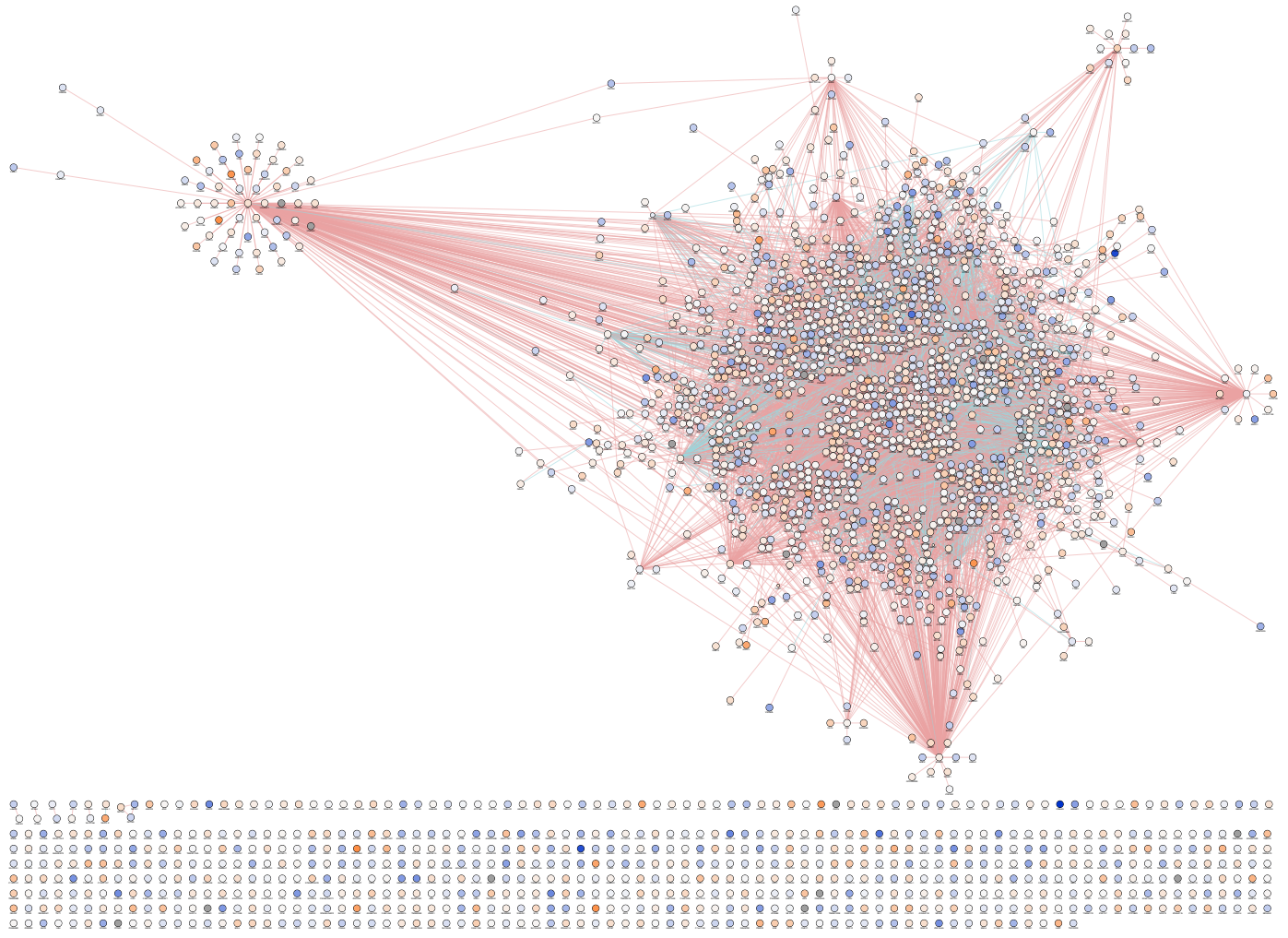

Figure 8. Clustering of genes with active proximal promoter merged regions. A total of 6062 active intervals were located upstream the gene sequence, of which 2210 were within proximal promoter regions $(-1 \mathrm{~kb}-0)$ indicating pro-transcriptional activity. Connectivity based on pathway (blue connectors) and physical interactions (red connectors) produced a cluster of 1540 genes. Changes in peak intensity in HIV+Meth+ compared to HIV+Meth- are shown by color (blue-decrease, orange-increase, white-no change). 


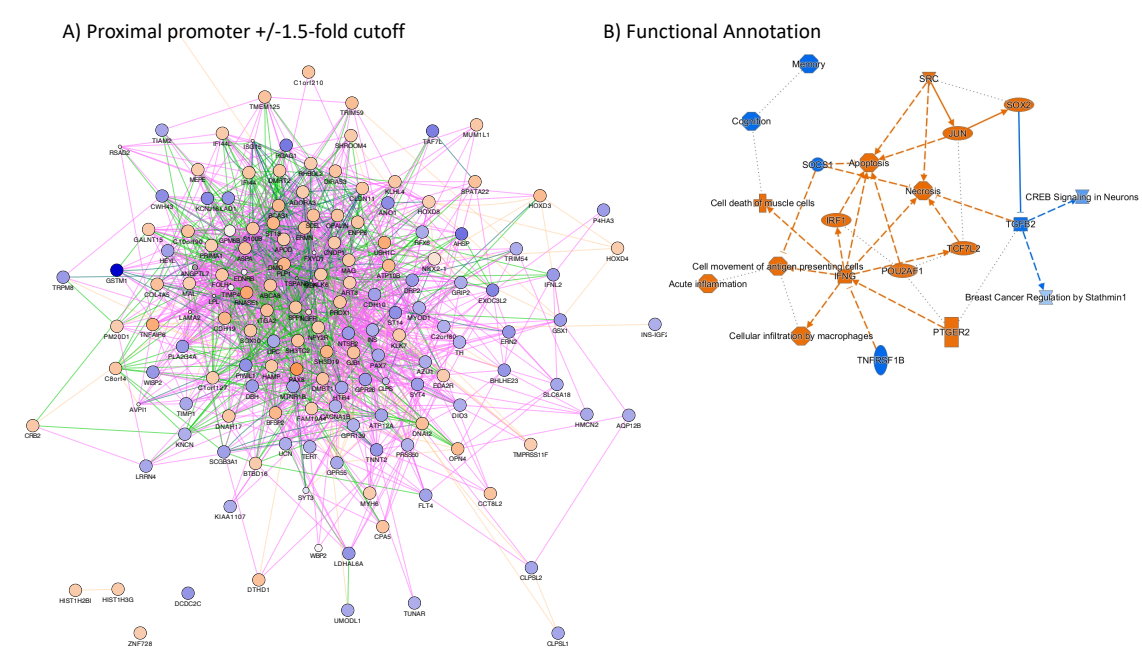

C) Dopaminergic synapse signatures

Figure 9. Network of genes with significant changes in H3K4me3 dynamics within the proximal promoter in HIV+Meth+ postmortem prefrontal cortex specimens compared to HIV+Meth-. (A) A weighted gene network from in-promoter enrichment patterns filtered to $+/-1.5$-fold differences, where circles in shades of blue indicate decrease, and shades of orange indicate enrichment, with relationships based on genetic interactions (pink edges), physical interactions (red edges) and pathway (green edges). (B) Functional Annotation derived from IPA related to genes with in-promoter modifications and prediction of transcriptional regulators. Edges indicate directional molecular and pathway (orange) and biological processes (blue) relationships. (C) Subnetwork containing dopaminergic synapse signatures showing in-promoter modifications, identified by grouped by genetic interactions (pink edges), physical interactions (red edges) and pathway (green edges) $\left(\right.$ KEGG, $\left.p=3.9 \times 10^{-6}\right)$. Node sizes represent connection scores. Blue colors indicate decrease and orange indicates increase in H3K4me3 peak signals in averaged HIV+Meth+ compared to HIV+Meth- prefrontal cortex specimens.

A second significant high-score node (4.8 score) identified among genes with proximal promoter activity and significant $><1.5$-fold changes was characterized by dopaminergic synapses signatures (Figure 9C), also including genes with both increased and decreased activity. In this node, decreased activity in the Tyrosine Hydroxylase (TH) and PAX7 promoters suggests a loss of dopaminergic function and neural progenitors in Meth users in the context of HIV [35]. In both high score nodes (Figure 9A,C), the color-coded line edges show the interaction criteria between the genes of interest, in these cases based predominantly in genetic and pathway interactions and indicating a coordinated process.

The unbiased analysis of all genes with $\mathrm{HeK} 4 \mathrm{me} 3$ active regions (Figure $6 \mathrm{E}$ ), regardless of position (in gene, downstream, upstream proximal or upstream distal, C1-C5), using a 1.5 cut off and $95 \%$ confidence level in detectable changes caused by Meth in the context of HIV, has led to the identification of several gene clusters and pathways annotated to addiction (Figure 10) and neuronal synapses (Figure 11), expressing a high degree of redundancy, which is evidenced by merging features. The systems analysis indicates differential activity in genes annotated to nicotine (Figure 10A), morphine (Figure 10B), amphetamine (Figure 10C) and cocaine (Figure 10D) addiction. These pathways have a high degree of overlapping interactions that could be merged into a single network (Figure 10E). 


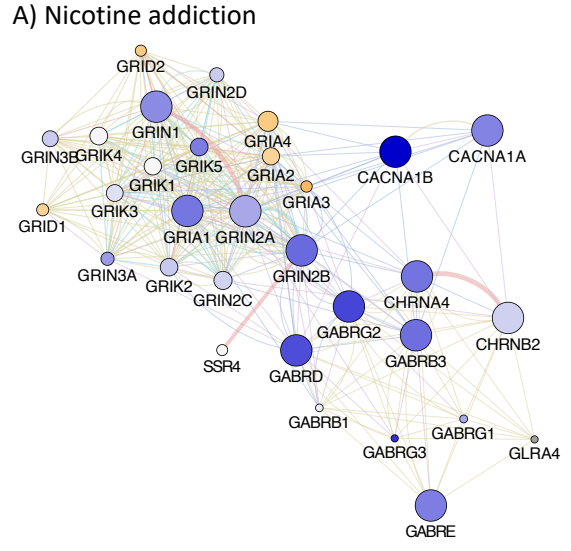

C) Amphetamine addiction
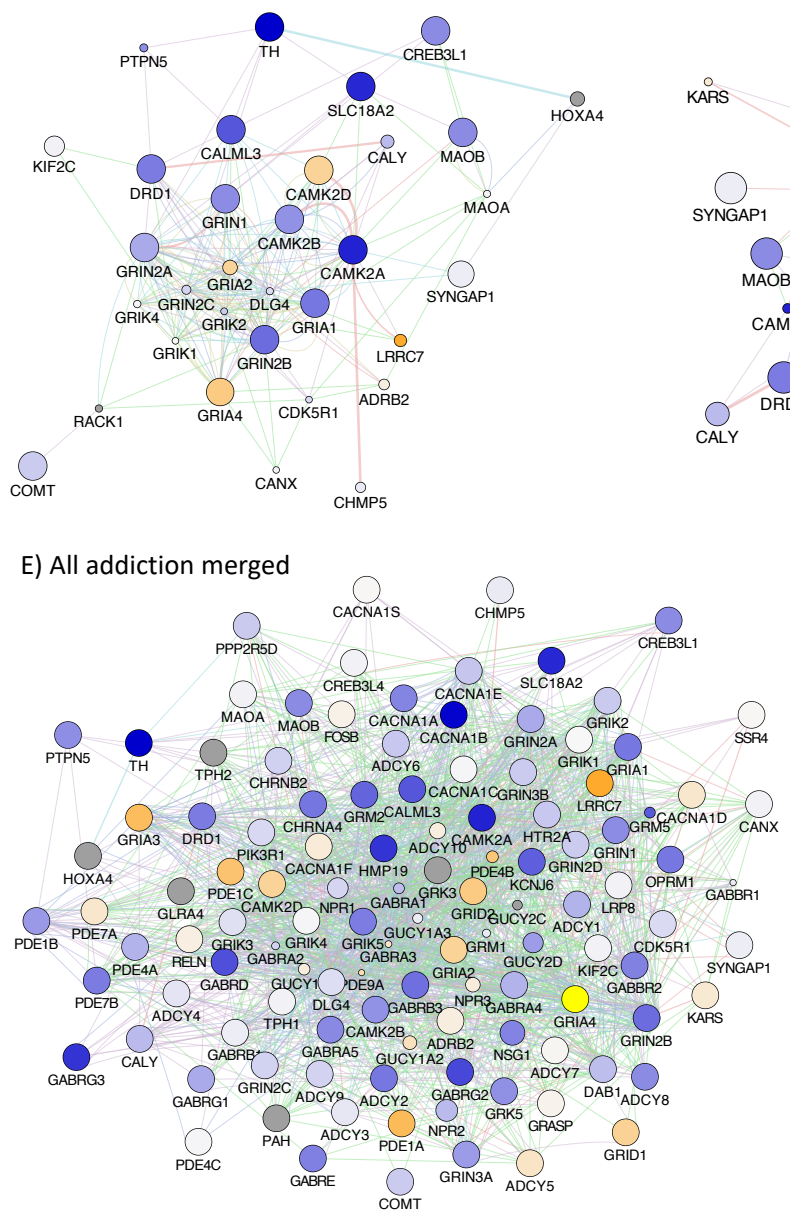

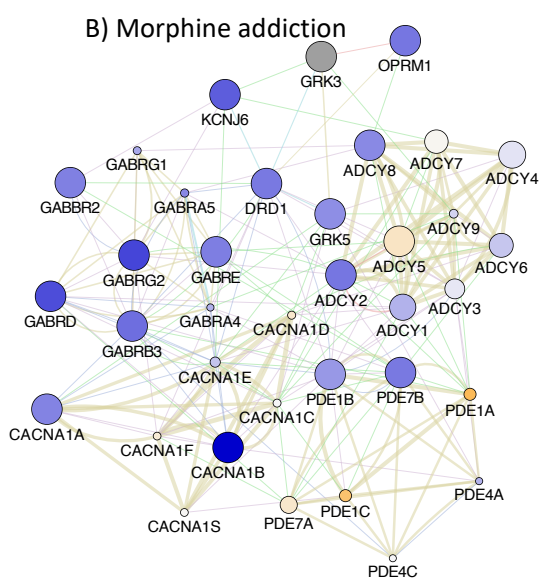

D) Cocaine addiction

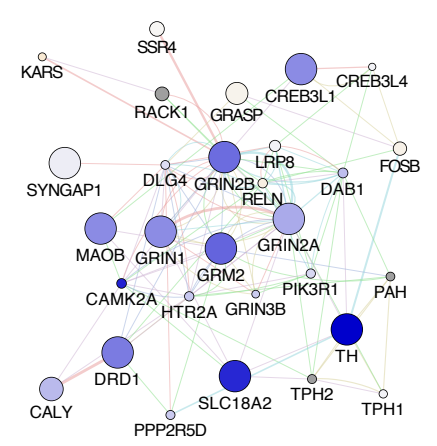

Figure 10. Gene clusters annotated to drug addiction pathways in HIV+ prefrontal cortex and the effect of Meth use. The analysis of genes with H3K4me3 active regions, including in-gene, downstream distal and proximal, as well as upstream has resulted in gene clusters annotated to addiction. Genes overrepresented in pathways associated to (A) Nicotine addiction $\left(p=2.2 \times 10^{-5}\right.$, Benjamini $\left.=7.6 \times 10^{-4}\right),($ B $)$ Morphine addiction $\left(p=1.9 \times 10^{-5}\right.$, Benjamini $\left.=1.3 \times 10^{-3}\right),(\mathbf{C})$ Amphetamine addiction $\left(p=1.4 \times 10^{-4}\right.$, Benjamini $\left.=6.1 \times 10^{-3}\right)$ and $(\mathrm{D})$ Cocaine addiction $\left(p=1.1 \times 10^{-3}\right.$, Benjamini $\left.=3 \times 10^{-2}\right)$. (E) These clusters showed a $56 \%$ overlap and $100 \%$ connectivity in merged features. Node sizes represent connection scores. Blue colors in nodes indicate decrease and orange indicates increase in H3K4me3 peak signals in averaged HIV+Meth+ compared to HIV+Meth- prefrontal cortex specimens. Gray nodes indicate genes in the pathway for which we have not detected any H3K4me3 peak signal. Edge colors represent interaction criteria in connectors as defined in the legend. 


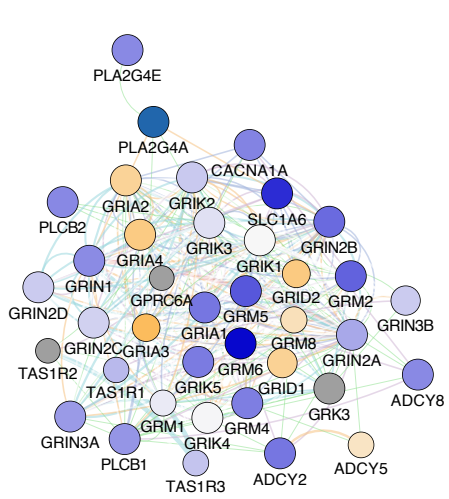

D) Serotoninergic synapse

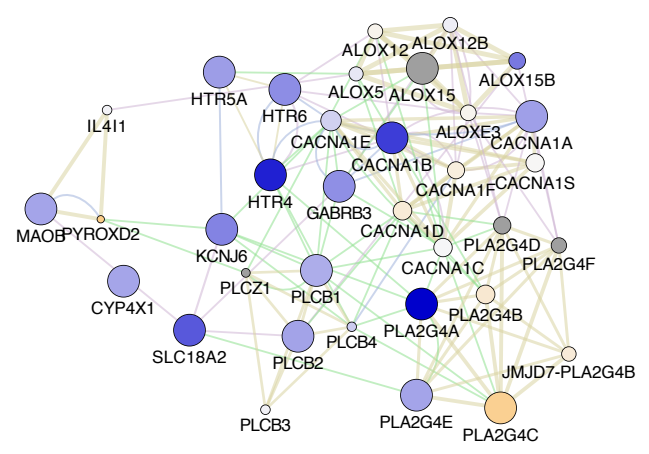

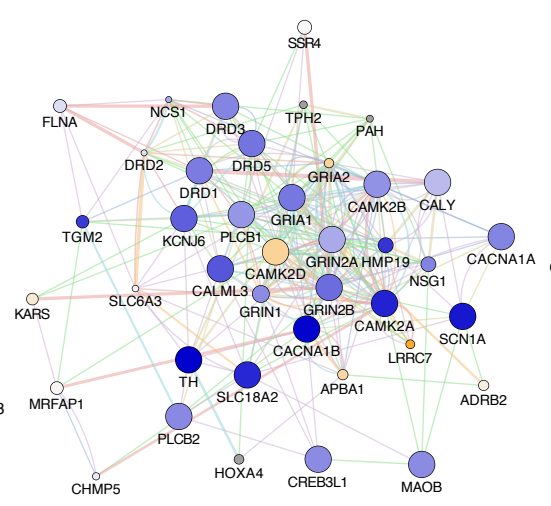

E) GABAergic synapse

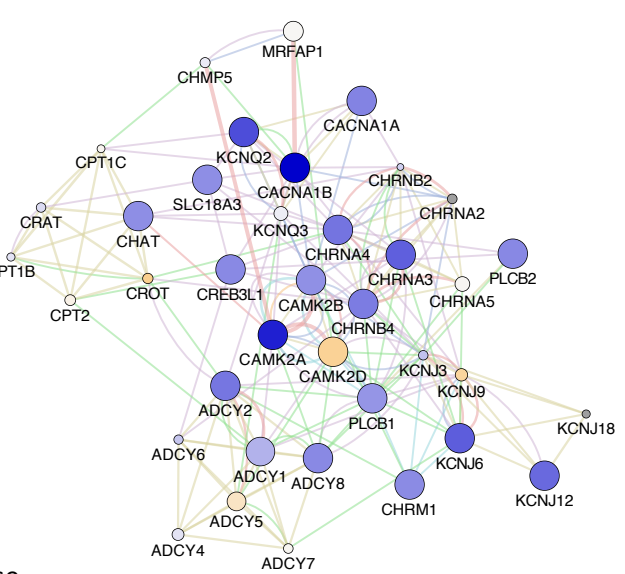

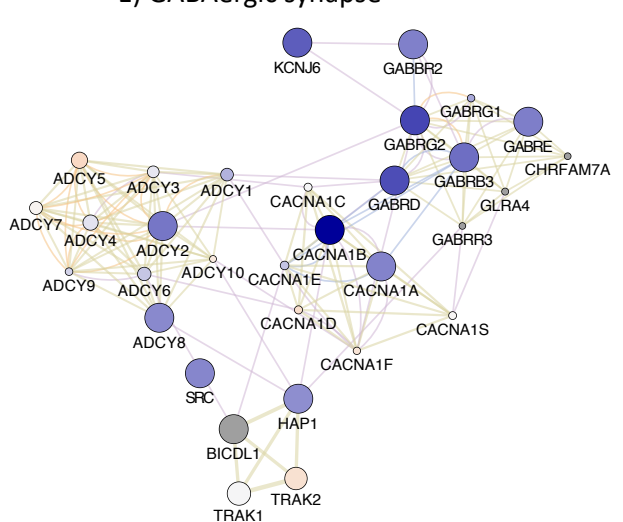

Shared protein domains Co-expression Co-localization Physical Interactions Predicted Pathway Genetic Interactions

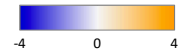

Figure 11. Gene clusters annotated to neurological synapses in HIV+ prefrontal cortex and the effect of Meth use. The analysis of genes with H3K4me3 active regions, including in-gene, downstream distal and proximal, as well as upstream, has resulted in gene clusters annotated to neurological synapses and function. Genes overrepresented in pathways associated to (A) Glutamatergic synapse $\left(p=5.6 \times 10^{-5}\right.$, Benjamini $\left.=1.310^{-3}\right),(\mathbf{B})$ Dopaminergic synapse $\left(p=2.2 \times 10^{-5}\right.$, Benjamini $\left.=7.6 \times 10^{-4}\right),(\mathbf{C})$ Cholinergic synapse $\left(p=3.9 \times 10^{-5}\right)$, Benjamini $\left.=1.2 \times 10^{-3}\right)$, (D) Serotoninergic synapse $\left(p=1.8 \times 10^{-3}\right.$, Benjamini $\left.=1.6 \times 10^{-2}\right)$ and $\left(\right.$ E) GABAergic synapse $\left(p=3.6 \times 10^{-4}\right.$, Benjamini $\left.=3.2 \times 10^{-2}\right)$.

Clusters annotated to synaptic pathways have also been able to distinguish HIV+Meth+ from HIV+Meth-, using the same approach including all merged HeK4me3 active regions (Figure 6E). For instance, high score gene clusters were annotated to glutamatergic (Figure 11A), dopaminergic (Figure 11B), cholinergic (Figure 11C), serotoninergic (Figure 11D), as well as GABAergic synapses (Figure 11E). Gene nodes were connected by protein-protein and genetic interactions, as well as pathway. Other high score pathways were annotated to neuronal functions, such as long-term potentiation (Figure 12A) and neuroactive ligand-receptor interactions (Figure 12B). The overlap between synaptic and neuroactive pathways was revealed by merging feature properties (Figure 12C). The large number of neural synapses genes with blue node color suggests that $\mathrm{H} 3 \mathrm{~K} 4 \mathrm{me} 3$ is decreased in the context of Meth. 


\section{A) Long-term potentiation}

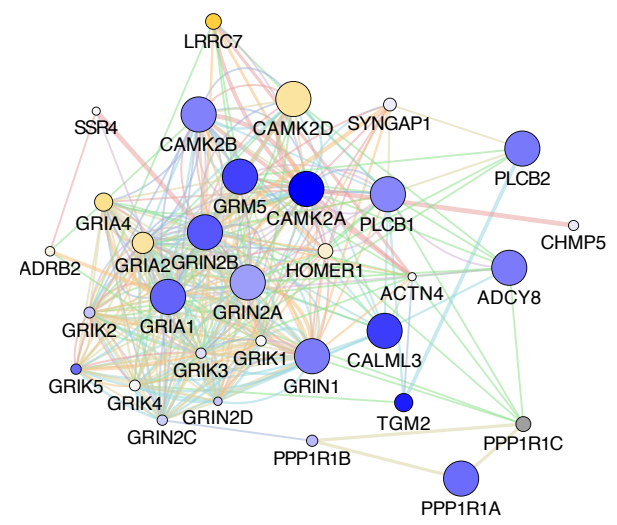

B) Neuroactive Ligand-Receptor Interactions

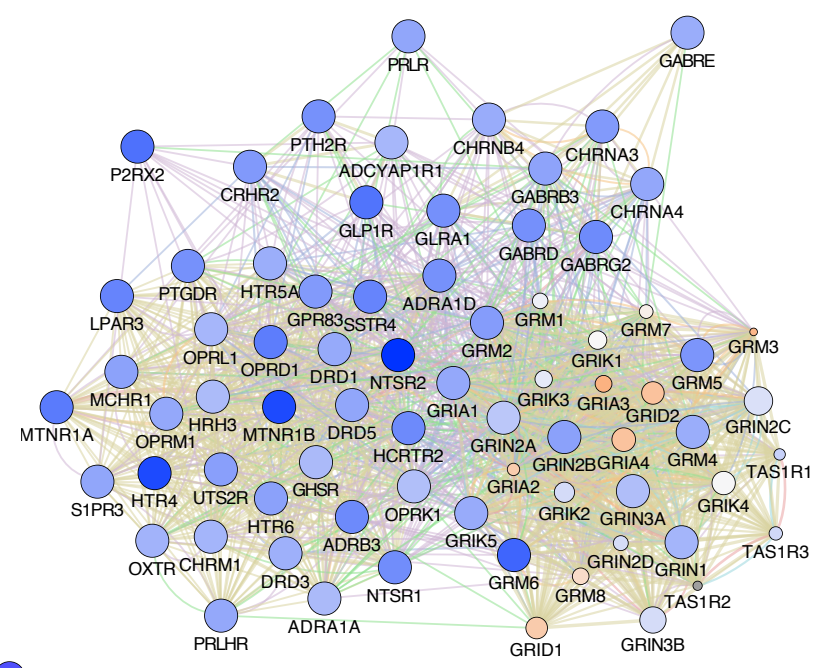

C) All Synapse Merged

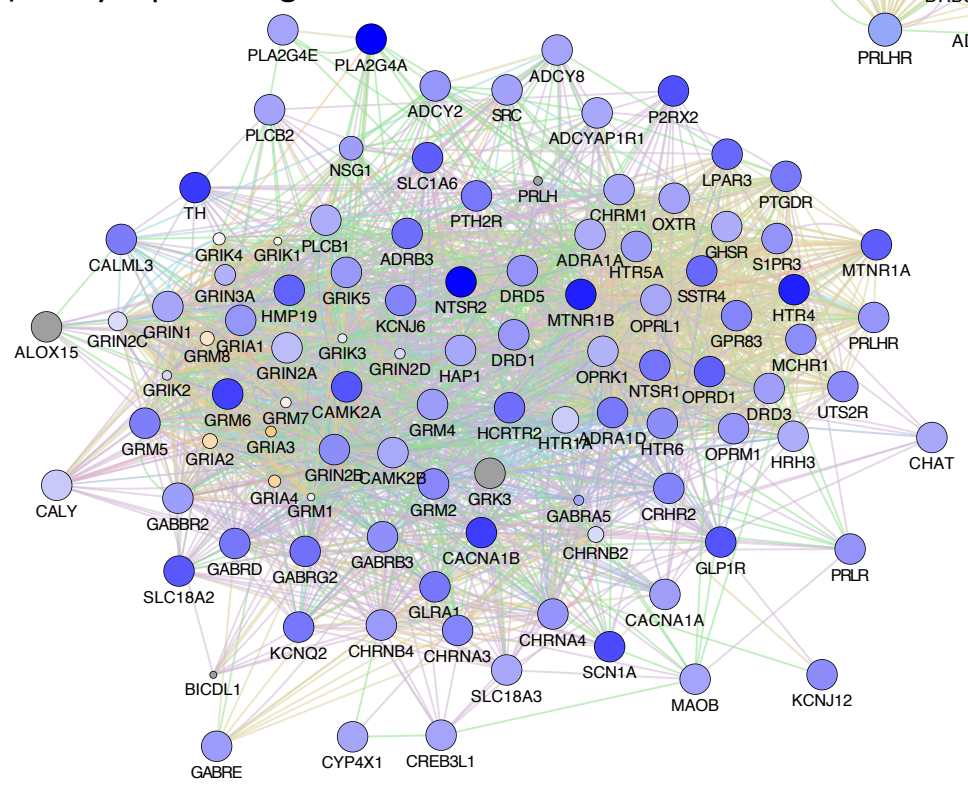

Shared protein domains

Co-expression

Co-localization

Physical Interactions

Predicted

Pathway

Genetic Interactions

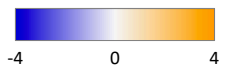

Figure 12. Gene clusters annotated to neurological functions. (A) Long-term potentiation $\left(p=1.4 \times 10^{-4}\right.$, Benjamini $\left.=6.2 \times 10^{-3}\right)$. (B) Neuroactive ligand-receptor interactions $\left(p=6.6 \times 10^{-18}\right.$, Benjamini $\left.=3.3 \times 10^{-16}\right) .($ C) Merged synaptic clusters indicating redundancy and common interactions. Clusters in Figures 11 and 12 showed a 52.7\% overlap and $100 \%$ connectivity in merged features. Node sizes represent connection scores. Blue colors indicate decrease and orange indicates increase in H3K4me3 peak signals in averaged HIV+Meth+ compared to HIV+Meth- prefrontal cortex specimens. Gray nodes indicate genes in the pathway for which we have not detected any H3K4me4 peak signal.

Interestingly, like with addiction pathways, neurological synapses genes showed a lower number of H3K4me3 active peak regions in the prefrontal cortex from HIV+Meth users compared to non-Meth users, suggesting differences in enhancer chromatin remodeling events, while epigenomic alterations such as the one we are measuring have the capacity to affect the behavior of the identified gene networks. However, epigenomic factors do it so in cooperation with transcription factors and the respective binding motifs made available by such modifications. ChIP data input in BED format into TRANSFAC generated a functional analysis report where prefrontal cortex was the most significantly over-represented attribute $\left(p=2.29 \times 10^{-26}\right)$. Cell type attributes characterized by the over-representation patterns included neurons $\left(p=1.86 \times 10^{-12}\right)$, followed by T cells $\left(p=3.93 \times 10^{-8}\right)$, while innate immune cells (macrophages/microglia) were significantly under-represented $\left(p=3.77 \times 10^{-6}\right)$, suggesting potential dysfunction in that compartment regardless of drug use patterns. 
To further help in the prediction of changes in the behavior of gene networks, and the effects of addiction, we modeled transcription factor usage to estimate the contribution of transcription factors affected and recruited by H3K4me3 in gene intervals, added 200bp flanking regions. For that, we used TRANSFAC Match algorithm, which determined the frequency of transcription factor binding motifs in H3K4me3 intervals aligned to the GRCh38 human genome assembly from the Genome Reference Consortium (GCA_000001405.15 GCF_000001405.26). Table 3 shows the 10 most frequent binding motifs, significantly represented in active genomic regions in both HIV+Meth- and Meth+ group specimens.

Table 3. List of 10 most frequent transcription factor binding motifs identified in $+/-200 \mathrm{bp}$ from and within H3K4me3 intervals in HIV+ Meth- and Meth+ specimens. The most frequent consensus sequences are presented, along with the average number of binding sites per interval sequence throughout the genome.

\begin{tabular}{ccccc}
\hline Matrix & Factor & Consensus Sequence & Classification & Average \#Sites Interval Sequence \\
\hline V\$SP1_13 & Sp1 & gcggctctgcggGGCGGggcggg & ZFC2H2 & 4.33 \\
\hline V\$P53_03 & P53 & cgACATGGacacacatgggt & P53 & 3.33 \\
\hline V\$ETS2_06 & c-Ets-2 & ggCCGGAgaggctgccctt & ETS & 2.85 \\
\hline V\$JUNDFRA2_01 & JUND:FRA2 & aaTGACTcaa & BZIP & 2.5 \\
\hline V\$ASCL1_03 & MASH-1 & cgCAGCTgcc & BHLH & 2.5 \\
\hline V\$NR3C1_13 & GR & aacacaataTGTACa & ZFC4-NR & 2.33 \\
\hline V\$CREBP1_01 & ATF-2 & tgaCGTCA & BZIP & 2.29 \\
\hline V\$AP2ALPHA_03 & AP2aA & cgCGCCCccggctct & BHSH & 2.27 \\
\hline V\$MYCMAX_03 & cMyc:Max & agttatgcACGTGtgtacca & BHLH & 2.15 \\
\hline V\$HOXA5_03 & HOXA5 & AATTAgtg & HOX & 2 \\
\hline
\end{tabular}

\section{Discussion}

Postmortem specimens from humans are a valuable resource for understanding molecular dynamics taking place in a diversity of conditions. Even more critical is the fact that large association studies benefit from the integration with transcriptional profiles. However, RNA quality has been a limitation, encountered by our group and others $[2,36,37]$. It has been shown that small differences in RNA integrity affect gene expression quantification by introducing a moderate and pervasive bias in expression level estimates [38]. Postmortem interval is a major factor affecting RNA quality, along with years of storage [36,39]. This is an important issue particularly in specimens from substance user populations, with very diverse characteristics of interest [40]. Our results suggest that predictions on the behavior of gene networks can be derived from specimens that have a limited use in transcriptional profiling studies, by comparing epigenetic marker patterns that are preserved over longer postmortem intervals [41].

Epigenetic modifications, enhancers and regulators of transcriptional activity are likely protected by protein-based mechanisms that prevent physical damage to the genome and evolutionarily tailored to maintain the stability of gene expression patterns [42]. We tested the postmortem availability and preservation of two enhancer histone modifications, $\mathrm{H} 3 \mathrm{H} 4 \mathrm{me} 3$ and $\mathrm{H} 3 \mathrm{~K} 27 \mathrm{Ac}$, as well as RNAPol II at the TSS, all regarded as strong correlates of gene expression activity, using ChIP in mouse and human brain specimens [43-45].

In our studies in mice with controlled postmortem intervals, we found that H3K4me3 was more abundant than other active chromatin modifications, followed by H3K27Ac, and by RNAPol binding. Although this may reflect a difference of stability [41] developed for the preservation of genomic information, other factors might explain a significant relative difference in the abundance of these marks. For instance, the abundance of H3K4me3 could be associated to the number of histone modifications required to produce changes in the chromatin architecture and prime RNAPol recruitment as a single event. It may be also 
possible that not every histone modification will result in productive remodeling, which may depend on additional factors. Nevertheless, differences in stability are suggested by the negative slope. For instance, the slope of RNAPol compared to histone modifications indicates a faster decay or loss. Nevertheless, at $96 \mathrm{~h}$ postmortem, significant loss in all measures indicated that $72 \mathrm{~h}$ was the maximum postmortem interval for retrieving reliable data. H3K4me3 was more abundant than H3K27Ac and was detectable in postmortem tissues with larger intervals up to $72 \mathrm{~h}$. The H3K4me3 epigenetic mark was also consistently found in human brain specimens with low RNA quality and used to examine frozen prefrontal cortex specimens preserved from HIV+ subjects.

A higher activity based on the number of H3K4me3 active sites was found in chromosome 1 , which is the largest human chromosome and reported involvement in heritable brain disorders [46]. Similarly, the highly active chromosome 19 contains genes such as APOE and Notch 3, whose polymorphisms have implications in, respectively, Alzheimer's disease (AD) $[47,48]$ and stroke and dementia associated with cerebral autosomal dominant arteriopathy with subcortical infarcts and leukoencephalopathy [49,50]. HIV neurocognitive disorders share biomarkers and have similarities with AD [51]. Nevertheless, Meth had no effect on APOE gene activity. The similarity regarding mean gene activities within different chromosomes and across subjects indicates that potential differences between the groups are likely not due to disrupted enhancing epigenetic mechanisms, and they can be used for comparisons. This is also evidenced by similar H3K4me3, H3K27Ac and RNAPol tag ratios in housekeeping genes between groups.

The analysis of H3K4me3 peak distribution was used predict signatures of Meth use disorder in the context of HIV. H3K4me3 promoter and gene activities are associated with transcriptional events in several systems $[43,52,53]$. Systems biology approaches were performed using activity that is exclusively in proximal promoters as well as including all gene regions. The majority of the in-promoter activity occurred in genes clustered in a large interactive network and annotated to inflammatory and viral responses, as well as to the dopaminergic system. Meth use was associated with enrichment of genomic activity in process-relevant genes such as IFNG and AATK, as well as loss of TH promoter activity [54], which is potentially associated with dopaminergic deficits. This finding suggests that Meth use increases genomic activities most likely to become transcriptional events that increase inflammation and apoptosis, with implications to neurodegeneration, dopaminergic deficits and decreased cognitive and executive functions, confirming previous observations from animal models of neuroHIV and from humans [55-61]. This indicates that epigenetic signatures are able to retrieve biologically meaningful data replicated by other systems and have the potential to provide incremental knowledge in association studies. In addition, this also suggests that biological processes associated with pathogenesis in the context of HIV and in drug users may have an epigenetic basis.

The majority of the promoter and gene activity evidenced by H3K4me3 peaks, was suppressed in HIV+ Meth users, compared to HIV+ non-Meth users. These results also parallel previous transcriptional findings in a mouse model of HIV and Meth abuse, where Meth caused a significant suppression of gene transcription [57,62], particularly regarding the dopaminergic system $[57,62,63]$. This was also evident when the analysis included H3K4me3 peaks in all different gene regions, including downstream, upstream distal and upstream proximal (promoter region), as well as in exons, addiction and neuronal synapses gene networks were specifically identified, suggesting that genomic activity measures like the one we performed here can help predict changes associated with addiction and synaptic disorders. For instance, we distinguished pathways involved in drugs of abuse, in addition to amphetamines, with a granular precision based on various degrees of interaction. Among the pathways showing changes in gene activity in correlation with Meth use, we have identified nicotine, cocaine and opioids. We cautiously interpret this finding given the limited knowledge about the subjects' history. However, polysubstance use is indeed prevalent among Meth abusers [64] and may be a factor. If this is the case, our strategy has the power to distinguish addictive disorders with a high degree of granularity. However, it 
is also important to acknowledge that molecular mechanisms involved in addiction have commonalities between different drugs [65-67]. This is evident in the overlap between addiction pathways, with common elements in reward circuitry and neurotransmitters.

The gene networks associated with individual synaptic functions exhibited a common behavior, characterized by an overall decrease in genomic activity in Meth users in the context of HIV. This could result from mechanisms that favor and enhance the inflammatory process, which were identified here, leading to neuronal loss, including in the dopaminergic system, a hallmark of Meth and other substance use disorders [68,69]. Importantly, the patterns associated with Meth use strongly suggest a decrease in synaptic strength. This weakening was detectable in both inhibitory and excitatory $\gamma$-aminobutyric acid (GABA) and glutamatergic synapses projected from other brain regions to the prefrontal cortex, which was examined here. Along with dopaminergic projections into the prefrontal cortex, neuroactive ligand-receptor interactions play an important role in cognition and learning [70], temporal organization of behavior [71-74], as well as executive functioning that form the basis of planning, reasoning and thinking. In this area, a balance in neurotransmitters and neural networks is critical for the stability of the neuronal activation in that brain region [75-77]. Similar changes in circuitry have been previously described in correlation with Meth and other psychostimulants [78]. Moreover, the dopaminergic system is independently affected by HIV, with a described impact on addiction behaviors $[79,80]$. While our work suggests an epigenetic basis for neuronal circuitry disorders, it also shows such disorders can be distinguished in the brain of Meth users in the context of HIV based on epigenomic activity.

In addition to the prediction of gene network behaviors, patterns of H3K4me4 peak activity can be used to predict transcription factor usage patterns, based on the occurrence of binding motif sequences within and near active intervals. We have performed this analysis and found that $\mathrm{Sp} 1$ was the most frequent binding motif. It has been shown that Sp1 makes a complex with NFkB to enhance HIV replication in vitro, in a process that is facilitated by Meth [81]. The second most abundant binding motif was p53, which has been described as a critical transcription factor in long term neurotoxic effects of Meth, particularly in dopaminergic neurons [82]. ETS2, which was another enriched binding motif, has been described as a transcriptional repressor of IL2 as well as of HIV, as it binds to the HIV-LTR-RATS element $[83,84]$. Thus, transcription factor binding predictions suggest potential important Meth effects on HIV replication and neurotoxicity.

This study has limitations, including small sample size and the lack of HIV-negative specimens. Our epigenetic findings can inform processes occurring in the human brain but must be integrated with transcriptome data in specimens and models with higher RNA quality stability for validation. Nevertheless, since a large fraction of the H3K4me3 genomic activity occurs in proximal promoters followed by introns, it is likely to result into and correspond to transcriptional events.

We demonstrate that important insights can be gained from epigenetic approaches and opens to the opportunity of investigations with larger sample sizes. We have shown the potential of using enhancer epigenetic marks for making predictions on the behavior of gene networks and for recovering important information from a significant number of specimens with limited use due to postmortem or storage intervals.

Supplementary Materials: The following are available online at https:/ / www.mdpi.com/1999-491 5/13/4/544/s1, Table S1: Proximal Promoter node, Table S2: All synapses default node, Table S3: All addiction default node. 
Author Contributions: L.B. participated in the concept, prepared all brain cell pellets for ChIP, performed pathway analysis using IPA and other strategies, performed in situ hybridizations and participated in discussions; A.L. performed in situ hybridizations, examined sections and participated in discussions; A.M.M. performed in situ hybridizations and examination of sections; R.J.E. participated in the design of the study, in the selection of human specimens and in discussions; M.C.G.M. elaborated the concept and hypothesis, participated in the design and selection of human specimens, processed frozen human prefrontal cortex fragments till pellets, dissected mouse brains, performed all the systems analysis on Cytoscape and TRANSFAC, wrote the manuscript and obtained funding. All authors have read and agreed to the published version of the manuscript.

Funding: R01DA036164 and R01DA047822 to M.C.G.M.

Institutional Review Board Statement: This study was performed under approved institutional IRB 20-001 MCM.

Informed Consent Statement: Not applicable.

Data Availability Statement: All data relevant to this manuscript is available in Supplementary Materials.

Acknowledgments: This study was supported by the R01DA036164 and R01DA047822 to M.C.G.M. The authors thank John Satterlee (National Institute on Drug Abuse, NIH) for discussions and suggestions, Madeleine Craske from Active Motif Inc. (Carlsbad, CA, USA) for technical advice and discussions, Fazila Kiyam, Krista Scrivner and Christine Auciello (San Diego Biomedical Research Institute, CA, USA) for administrative assistance.

Conflicts of Interest: The authors declare no conflict of interest.

\section{References}

1. Fan, J.; Khanin, R.; Sakamoto, H.; Zhong, Y.; Michael, C.; Pena, D.; Javier, B.; Wood, L.D.; Iacobuzio-Donahue, C.A. Quantification of nucleic acid quality in postmortem tissues from a cancer research autopsy program. Oncotarget 2016, 7, 66906-66921. [CrossRef]

2. Zhu, Y.; Wang, L.; Yin, Y.; Yang, E. Systematic analysis of gene expression patterns associated with postmortem interval in human tissues. Sci. Rep. 2017, 7, 1-12. [CrossRef]

3. Tolliver, S.S.; Hearn, W.L.; Furton, K.G. Evaluating the Relationship Between Postmortem and Antemortem Morphine and Codeine Concentrations in Whole Blood. J. Anal. Toxicol. 2010, 34, 491-497. [CrossRef] [PubMed]

4. Gates, L.A.; Foulds, C.E.; O'Malley, B.W. Histone Marks in the 'Driver's Seat': Functional Roles in Steering the Transcription Cycle. Trends Biochem. Sci. 2017, 42, 977-989. [CrossRef] [PubMed]

5. Karlić, R.; Chung, H.-R.; Lasserre, J.; Vlahoviček, K.; Vingron, M. Histone modification levels are predictive for gene expression. Proc. Natl. Acad. Sci. USA 2010, 107, 2926-2931. [CrossRef] [PubMed]

6. Huebert, D.J.; Kamal, M.; O’Donovan, A.; Bernstein, B.E. Genome-wide analysis of histone modifications by ChIP-on-chip. Methods 2006, 40, 365-369. [CrossRef] [PubMed]

7. Bernstein, B.E.; Kamal, M.; Lindblad-Toh, K.; Bekiranov, S.; Bailey, D.K.; Huebert, D.J.; McMahon, S.; Karlsson, E.K.; Kulbokas, E.J.; Gingeras, T.R.; et al. Genomic Maps and Comparative Analysis of Histone Modifications in Human and Mouse. Cell 2005, 120, 169-181. [CrossRef]

8. Bernstein, B.E.; Humphrey, E.L.; Liu, C.L.; Schreiber, S.L. The use of Chromatin Immunoprecipitation Assays in Genome-Wide Analyses of Histone Modifications. Methods Enzym. 2003, 376, 349-360. [CrossRef]

9. Bernstein, B.E.; Humphrey, E.L.; Erlich, R.L.; Schneider, R.; Bouman, P.; Liu, J.S.; Kouzarides, T.; Schreiber, S.L. Methylation of histone H3 Lys 4 in coding regions of active genes. Proc. Natl. Acad. Sci. USA 2002, 99, 8695-8700. [CrossRef] [PubMed]

10. Hightower, G.K.; Wong, J.K.; Letendre, S.L.; Umlauf, A.A.; Ellis, R.J.; Ignacio, C.C.; Heaton, R.K.; Collier, A.C.; Marra, C.M.; Clifford, D.B.; et al. Higher HIV-1 genetic diversity is associated with AIDS and neuropsychological impairment. Virology 2012, 433, 498-505. [CrossRef]

11. Everall, I.; Vaida, F.; Khanlou, N.; Lazzaretto, D.; Achim, C.; Letendre, S.; Moore, D.; Ellis, R.; Cherner, M.; Gelman, B.; et al. Cliniconeuropathologic correlates of human immunodeficiency virus in the era of antiretroviral therapy. J. Neurovirol. 2009, 15, 360-370. [CrossRef] [PubMed]

12. Gelman, B.B.; Chen, T.; Lisinicchia, J.G.; Soukup, V.M.; Carmical, J.R.; Starkey, J.M.; Masliah, E.; Commins, D.L.; Brandt, D.; Grant, I.; et al. The National Neuro AIDS Tissue Consortium Brain Gene Array: Two Types of HIV-Associated Neurocognitive Impairment. PLoS ONE 2012, 7, e46178. [CrossRef] [PubMed]

13. May, P.E.; Heithoff, A.J.; Wichman, C.S.; Phatak, V.S.; Moore, D.J.; Heaton, R.K.; Fox, H.S. Assessing Cognitive Functioning in People Living with HIV (PLWH): Factor Analytic Results From CHARTER and NNTC Cohorts. JAIDS J. Acquir. Immune Defic. Syndr. 2020, 83, 251-259. [CrossRef] [PubMed] 
14. Basova, L.; Najera, J.A.; Bortell, N.; Wang, D.; Moya, R.; Lindsey, A.; Semenova, S.; Ellis, R.J.; Marcondes, M.C.G. Dopamine and its receptors play a role in the modulation of CCR5 expression in innate immune cells following exposure to Methamphetamine: Implications to HIV infection. PLoS ONE 2018, 13, e0199861. [CrossRef] [PubMed]

15. Tjitro, R.; Campbell, L.A.; Basova, L.; Johnson, J.; Najera, J.A.; Lindsey, A.; Marcondes, M.C.G. Modeling the Function of TATA Box Binding Protein in Transcriptional Changes Induced by HIV-1 Tat in Innate Immune Cells and the Effect of Methamphetamine Exposure. Front. Immunol. 2019, 9, 3110. [CrossRef] [PubMed]

16. Zhang, Y.; Liu, T.A.; Meyer, C.; Eeckhoute, J.; Johnson, D.S.; Bernstein, B.E.; Nussbaum, C.; Myers, R.M.; Brown, M.; Li, W.; et al. Model-based Analysis of ChIP-Seq (MACS). Genome Biol. 2008, 9, 1-9. [CrossRef] [PubMed]

17. Zang, C.; Schones, D.E.; Zeng, C.; Cui, K.; Zhao, K.; Peng, W. A clustering approach for identification of enriched domains from histone modification ChIP-Seq data. Bioinformatics 2009, 25, 1952-1958. [CrossRef]

18. Sepulveda, J.L. Using R and Bioconductor in Clinical Genomics and Transcriptomics. J. Mol. Diagn. 2020, 22, 3-20. [CrossRef]

19. Montojo, J.; Zuberi, K.; Rodriguez, H.; Bader, G.D.; Morris, Q. GeneMANIA: Fast gene network construction and function prediction for Cytoscape. F1000Research 2014, 3, 153. [CrossRef]

20. Warde-Farley, D.; Donaldson, S.L.; Comes, O.; Zuberi, K.; Badrawi, R.; Chao, P.; Franz, M.; Grouios, C.; Kazi, F.; Lopes, C.T.; et al. The GeneMANIA prediction server: Biological network integration for gene prioritization and predicting gene function. Nucleic Acids Res. 2010, 38, W214-W220. [CrossRef]

21. Franz, M.; Rodriguez, H.; Lopes, C.; Zuberi, K.; Montojo, J.; Bader, G.D.; Morris, Q. GeneMANIA update 2018. Nucleic Acids Res. 2018, 46, W60-W64. [CrossRef]

22. Shannon, P.; Markiel, A.; Ozier, O.; Baliga, N.S.; Wang, J.T.; Ramage, D.; Amin, N.; Schwikowski, B.; Ideker, T. Cytoscape: A Software Environment for Integrated Models of Biomolecular Interaction Networks. Genome Res. 2013, 13, 2498-2504. [CrossRef]

23. Stein, L.D. Using the Reactome Database. Curr. Protoc. Bioinform. 2004, 7. [CrossRef]

24. Oughtred, R.; Rust, J.; Chang, C.; Breitkreutz, B.; Stark, C.; Willems, A.; Boucher, L.; Leung, G.; Kolas, N.; Zhang, F.; et al. The BioGRID database: A comprehensive biomedical resource of curated protein, genetic, and chemical interactions. Protein Sci. 2021, 30, 187-200. [CrossRef]

25. Oughtred, R.; Stark, C.; Breitkreutz, B.-J.; Rust, J.; Boucher, L.; Chang, C.; Kolas, N.; O’Donnell, L.; Leung, G.; McAdam, R.; et al. The BioGRID interaction database: 2019 update. Nucleic Acids Res. 2019, 47, D529-D541. [CrossRef]

26. Stark, C.; Breitkreutz, B.J.; Reguly, T.; Boucher, L.; Breitkreutz, A.; Tyers, M. BioGRID: A general repository for interaction datasets. Nucleic Acids Res. 2006, 34, D535-D539. [CrossRef]

27. Matys, V. Transfac (R) and its module TransCompel (R): Transcriptional gene regulation in eukaryotes. Nucleic Acids Res. 2006, 34, D108-D110. [CrossRef]

28. Wingender, E.; Chen, X.; Fricke, E.; Geffers, R.; Hehl, R.; Liebich, I.; Krull, M.; Matys, V.; Michael, H.; Ohnhäuser, R.; et al. The Transfac system on gene expression regulation. Nucleic Acids Res. 2001, 29, 281-283. [CrossRef] [PubMed]

29. Wingender, E. Transfac: An integrated system for gene expression regulation. Nucleic Acids Res. 2000, 28, 316-319. [CrossRef] [PubMed]

30. Fornes, O.A.; Castro-Mondragon, J.; Khan, A.; Van Der Lee, R.; Zhang, X.A.; Richmond, P.; Modi, B.P.; Correard, S.; Gheorghe, M.; Baranašić, D.; et al. Jaspar 2020: Update of the open-access database of transcription factor binding profiles. Nucleic Acids Res. 2019, 48, D87-D92. [CrossRef] [PubMed]

31. Wang, F.; Flanagan, J.; Su, N.; Wang, L.-C.; Bui, S.; Nielson, A.; Wu, X.; Vo, H.-T.; Ma, X.-J.; Luo, Y. RNAscope. J. Mol. Diagn. 2012, 14, 22-29. [CrossRef] [PubMed]

32. Brands, C.; Morcock, D.; Estes, J.; Deleage, C. Next-generation Viral RNA/DNA in situ Hybridization Applications in Human Immunodeficiency Virus/Simian Immunodeficiency Virus Research. J. Vis. Exp. 2020, 160. [CrossRef] [PubMed]

33. Deleage, C.; Chan, C.N.; Busman-Sahay, K.; Estes, J.D. Next-generation in situ hybridization approaches to define and quantify HIV and SIV reservoirs in tissue microenvironments. Retrovirology 2018, 15, 1-10. [CrossRef]

34. Mendoza-Parra, M.A.; Saleem, M.-A.M.; Blum, M.; Cholley, P.-E.; Gronemeyer, H. NGS-QC Generator: A Quality Control System for ChIP-Seq and Related Deep Sequencing-Generated Datasets. Adv. Struct. Saf. Stud. 2016, 1418, 243-265. [CrossRef]

35. Andersson, E.; Tryggvason, U.; Deng, Q.; Friling, S.; Alekseenko, Z.; Robert, B.; Perlmann, T.; Ericson, J. Identification of Intrinsic Determinants of Midbrain Dopamine Neurons. Cell 2006, 124, 393-405. [CrossRef]

36. Koppelkamm, A.; Vennemann, B.; Lutz-Bonengel, S.; Fracasso, T.; Vennemann, M. RNA integrity in post-mortem samples: Influencing parameters and implications on RT-qPCR assays. Int. J. Leg. Med. 2011, 125, 573-580. [CrossRef]

37. Ferrer, I.; Martinez, A.; Boluda, S.; Parchi, P.; Barrachina, M. Brain banks: Benefits, limitations and cautions concerning the use of post-mortem brain tissue for molecular studies. Cell Tissue Bank. 2008, 9, 181-194. [CrossRef]

38. Reiman, M.; Laan, M.; Rull, K.; Sõber, S. Effects of RNA integrity on transcript quantification by total RNA sequencing of clinically collected human placental samples. FASEB J. 2017, 31, 3298-3308. [CrossRef]

39. White, K.; Yang, P.; Li, L.; Farshori, A.; Medina, A.E.; Zielke, H.R. Effect of Postmortem Interval and Years in Storage on RNA Quality of Tissue at a Repository of the NIH NeuroBioBank. Biopreserv. Biobank. 2018, 16, 148-157. [CrossRef] [PubMed]

40. Ahlner, J.; Holmgren, A.; Jones, A.W. Demographics and post-mortem toxicology findings in deaths among people arrested multiple times for use of illicit drugs and/or impaired driving. Forensic Sci. Int. 2016, 265, 138-143. [CrossRef]

41. Jarmasz, J.S.; Stirton, H.; Davie, J.R.; Del Bigio, M.R. DNA methylation and histone post-translational modification stability in post-mortem brain tissue. Clin. Epigenet. 2019, 11, 5. [CrossRef] [PubMed] 
42. Almouzni, G.; Cedar, H. Maintenance of Epigenetic Information. Cold Spring Harb. Perspect. Biol. 2016, 8, a019372. [CrossRef] [PubMed]

43. Chen, K.; Chen, Z.; Wu, D.; Zhang, L.; Lin, X.; Su, J.; Rodriguez, B.; Xi, Y.; Xia, Z.; Chen, X.; et al. Broad H3K4me3 is associated with increased transcription elongation and enhancer activity at tumor-suppressor genes. Nat. Genet. 2015, 47, 1149-1157. [CrossRef]

44. Sato, Y.; Hilbert, L.; Oda, H.; Wan, Y.; Heddleston, J.M.; Chew, T.-L.; Zaburdaev, V.; Keller, P.; Lionnet, T.; Vastenhouw, N.; et al. Histone H3K27 acetylation precedes active transcription during zebrafish zygotic genome activation as revealed by live-cell analysis. Development 2019, 146, dev179127. [CrossRef]

45. Nikolov, D.B.; Burley, S.K. RNA polymerase II transcription initiation: A structural view. Proc. Natl. Acad. Sci. USA 1997, 94, 15-22. [CrossRef] [PubMed]

46. Klar, A.J.S. The chromosome 1;11 translocation provides the best evidence supporting genetic etiology for schizophrenia and bipolar affective disorders. Genetics 2002, 160, 1745-1747. [PubMed]

47. Lacour, A.; Espinosa, A.; Louwersheimer, E.; Heilmann, S.; Hernández, I.; Wolfsgruber, S.; Fernández, V.; Wagner, H.; RosendeRoca, M.; Mauleón, A.; et al. Genome-wide significant risk factors for Alzheimer's disease: Role in progression to dementia due to Alzheimer's disease among subjects with mild cognitive impairment. Mol. Psychiatry 2017, 22, 153-160. [CrossRef]

48. Moreno-Grau, S.M.-G.; Hernández, I.; Heilmann-Heimbach, S.; Ruiz, S.; Rosende-Roca, M.; Mauleón, A.; Vargas, L.; Gómez, O.R.; Alegret, M.; Espinosa, A.; et al. Genome-wide significant risk factors on chromosome 19 and the APOE locus. Oncotarget 2018, 9 , 24590-24600. [CrossRef]

49. Joutel, A.; Corpechot, C.; Ducros, A.; Vahedi, K.; Chabriat, H.; Mouton, P.; Alamowitch, S.; Domenga, V.; Cécillion, M.; Maréchal, E.; et al. Notch3 Mutations in Cerebral Autosomal Dominant Arteriopathy with Subcortical Infarcts and Leukoencephalopathy (CADASIL), a Mendelian Condition Causing Stroke and Vascular Dementia. Ann. N. Y. Acad. Sci. 1997, 826, 213-217. [CrossRef]

50. Joutel, A.; Corpechot, C.; Ducros, A.; Vahedi, K.; Chabriat, H.; Mouton, P.; Alamowitch, S.; Domenga, V.; Cécillion, M.; Maréchal, E.; et al. Notch3 mutations in CADASIL, a hereditary adult-onset condition causing stroke and dementia. Nat. Cell Biol. 1996, 383, 707-710. [CrossRef]

51. Canet, G.; Dias, C.; Gabelle, A.; Simonin, Y.; Gosselet, F.; Marchi, N.; Makinson, A.; Tuaillon, E.; Van De Perre, P.; Givalois, L.; et al. HIV Neuroinfection and Alzheimer's Disease: Similarities and Potential Links? Front. Cell. Neurosci. 2018, 12, 307. [CrossRef] [PubMed]

52. Okitsu, C.Y.; Hsieh, J.C.F.; Hsieh, C.-L. Transcriptional Activity Affects the H3K4me3 Level and Distribution in the Coding Region. Mol. Cell. Biol. 2010, 30, 2933-2946. [CrossRef] [PubMed]

53. Akkers, R.C.; Van Heeringen, S.J.; Jacobi, U.G.; Janssen-Megens, E.M.; Françoijs, K.-J.; Stunnenberg, H.G.; Veenstra, G.J.C. A Hierarchy of H3K4me3 and H3K27me3 Acquisition in Spatial Gene Regulation in Xenopus Embryos. Dev. Cell 2009, 17, 425-434. [CrossRef] [PubMed]

54. Daubner, S.C.; Le, T.; Wang, S. Tyrosine hydroxylase and regulation of dopamine synthesis. Arch. Biochem. Biophys. 2011, 508, 1-12. [CrossRef]

55. Najera, J.A.; Bustamante, E.A.; Bortell, N.; Morsey, B.; Fox, H.S.; Ravasi, T.; Marcondes, M.C.G. Methamphetamine abuse affects gene expression in brain-derived microglia of SIV-infected macaques to enhance inflammation and promote virus targets. $B M C$ Immunol. 2016, 17, 1-19. [CrossRef]

56. Bortell, N.; Morsey, B.; Basova, L.; Fox, H.S.; Marcondes, M.C.G. Phenotypic changes in the brain of SIV-infected macaques exposed to methamphetamine parallel macrophage activation patterns induced by the common gamma-chain cytokine system. Front. Microbiol. 2015, 6, 900. [CrossRef]

57. Kesby, J.P.; Najera, J.A.; Romoli, B.; Fang, Y.; Basova, L.; Birmingham, A.; Marcondes, M.C.G.; Dulcis, D.; Semenova, S. HIV-1 TAT protein enhances sensitization to methamphetamine by affecting dopaminergic function. Brain Behav. Immun. 2017, 65, $210-221$. [CrossRef]

58. Mediouni, S.; Marcondes, M.C.G.; Miller, C.A.; McLaughlin, J.P.; Valente, S.T. The cross-talk of HIV-1 Tat and methamphetamine in HIV-associated neurocognitive disorders. Front. Microbiol. 2015, 6, 1164. [CrossRef]

59. Ellis, C.; Hoffman, W.; Jaehnert, S.; Plagge, J.; Loftis, J.M.; Schwartz, D.; Huckans, M. Everyday Problems with Executive Dysfunction and Impulsivity in Adults Recovering from Methamphetamine Addiction. Addict. Disord. Their Treat. 2016, 15, 1-5. [CrossRef]

60. Kohno, M.; Loftis, J.M.; Huckans, M.; Dennis, L.E.; McCready, H.; Hoffman, W.F. The relationship between interleukin-6 and functional connectivity in methamphetamine users. Neurosci. Lett. 2018, 677, 49-54. [CrossRef] [PubMed]

61. Loftis, J.M.; Janowsky, A. Neuroimmune Basis of Methamphetamine Toxicity. Int. Rev. Neurobiol. 2014, 118, 165-197. [CrossRef] [PubMed]

62. Basova, L.V.; Kesby, J.P.; Kaul, M.; Semenova, S.; Marcondes, M.C.G. Systems Biology Analysis of the Antagonizing Effects of HIV-1 Tat Expression in the Brain over Transcriptional Changes Caused by Methamphetamine Sensitization. Viruses 2020, $12,426$. [CrossRef]

63. Baek, E.J.; Kim, H.; Basova, L.A.; Rosander, A.; Kesby, J.P.; Semenova, S.; Marcondes, M.C.G. Sex differences and Tat expression affect dopaminergic receptor expression and response to antioxidant treatment in methamphetamine-sensitized HIV Tat transgenic mice. Neuropharmacology 2020, 178, 108245. [CrossRef] [PubMed] 
64. Blackstone, K.; Iudicello, J.E.; Morgan, E.E.; Weber, E.; Moore, D.J.; Franklin, D.R.; Ellis, R.J.; Grant, I.; Woods, S.P. Human Immunodeficiency Virus Infection Heightens Concurrent Risk of Functional Dependence in Persons with Long-Term Methamphetamine use. J. Addict. Med. 2013, 7, 255-263. [CrossRef] [PubMed]

65. Koob, G.F.; Volkow, N.D. Neurocircuitry of Addiction. Neuropsychopharmacology 2009, 35, 217-238. [CrossRef]

66. Koob, G.F.; Volkow, N.D. Neurobiology of addiction: A neurocircuitry analysis. Lancet Psychiatry 2016, 3, 760-773. [CrossRef]

67. Volkow, N.D.; Koob, G.; Baler, R. Biomarkers in Substance Use Disorders. ACS Chem. Neurosci. 2015, 6, 522-525. [CrossRef]

68. Nickoloff-Bybel, E.A.; Calderon, T.M.; Gaskill, P.J.; Berman, J.W. HIV Neuropathogenesis in the Presence of a Disrupted Dopamine System. J. Neuroimmune Pharmacol. 2020, 15, 729-742. [CrossRef]

69. Gonçalves, J.; Baptista, S.; Martins, T.; Milhazes, N.; Borges, F.; Ribeiro, C.F.; Malva, J.O.; Silva, A.P. Methamphetamine-induced neuroinflammation and neuronal dysfunction in the mice hippocampus: Preventive effect of indomethacin. Eur. J. Neurosci. 2010, 31, 315-326. [CrossRef] [PubMed]

70. Ott, T.; Nieder, A. Dopamine and Cognitive Control in Prefrontal Cortex. Trends Cogn. Sci. 2019, 23, 213-234. [CrossRef] [PubMed]

71. Fuster, J.M. The Prefrontal Cortex-An Update. Neuron 2001, 30, 319-333. [CrossRef]

72. Fuster, J.M. Memory networks in the prefrontal cortex. Prog. Brain Res. 2000, 122, 309-316. [CrossRef]

73. Fuster, J.M. Prefrontal Cortex and the Bridging of Temporal Gaps in the Perception-Action Cycle. Ann. N. Y. Acad. Sci. 1990, 608, 318-336. [CrossRef]

74. Goldman-Rakic, P.S. Architecture of the Prefrontal Cortex and the Central Executive. Ann. N. Y. Acad. Sci. 1995, 769, 71-84. [CrossRef] [PubMed]

75. Lisman, J.E.; Fellous, J.-M.; Wang, X.-J. A role for NMDA-receptor channels in working memory. Nat. Neurosci. 1998, 1, $273-275$. [CrossRef]

76. Tegnér, J.; Compte, A.; Wang, X.-J. The dynamical stability of reverberatory neural circuits. Biol. Cybern. 2002, 87, 471-481. [CrossRef]

77. Rolls, E.T.; Loh, M.; Deco, G.; Winterer, G. Computational models of schizophrenia and dopamine modulation in the prefrontal cortex. Nat. Rev. Neurosci. 2008, 9, 696-709. [CrossRef]

78. Wearne, T.A.; Cornish, J.L. Inhibitory regulation of the prefrontal cortex following behavioral sensitization to amphetamine and/or methamphetamine psychostimulants: A review of GABAergic mechanisms. Prog. Neuro-Psychopharmacol. Biol. Psychiatry 2019, 95, 109681. [CrossRef] [PubMed]

79. Gelman, B.B.; Lisinicchia, J.G.; Chen, T.; Johnson, K.M.; Jennings, K.; Freeman, D.H.; Soukup, V.M. Prefrontal Dopaminergic and Enkephalinergic Synaptic Accommodation in HIV-associated Neurocognitive Disorders and Encephalitis. J. Neuroimmune Pharmacol. 2012, 7, 686-700. [CrossRef] [PubMed]

80. Gelman, B.B.; Spencer, J.A.; Holzer, C.E.; Soukup, V.M.; Iii, C.E.H. Abnormal Striatal Dopaminergic Synapses in National NeuroAIDS Tissue Consortium Subjects with HIV Encephalitis. J. Neuroimmune Pharmacol. 2006, 1, 410-420. [CrossRef] [PubMed]

81. Skowronska, M.; McDonald, M.; Velichkovska, M.; Leda, A.R.; Park, M.; Toborek, M. Methamphetamine increases HIV infectivity in neural progenitor cells. J. Biol. Chem. 2018, 293, 296-311. [CrossRef] [PubMed]

82. Hirata, H.; Cadet, J.L. p53-knockout mice are protected against the long-term effects of methamphetamine on dopaminergic terminals and cell bodies. J. Neurochem. 2002, 69, 780-790. [CrossRef] [PubMed]

83. Panagoulias, I.; Karagiannis, F.; Aggeletopoulou, I.; Georgakopoulos, T.; Argyropoulos, C.P.; Akinosoglou, K.; Gogos, C.; Skoutelis, A.; Mouzaki, A. Ets-2 Acts as a Transcriptional Repressor of the Human Immunodeficiency Virus Type 1 through Binding to a Repressor-Activator Target Sequence of 5'-LTR. Front. Immunol. 2018, 8, 1924. [CrossRef]

84. Panagoulias, I.; Georgakopoulos, T.; Aggeletopoulou, I.; Agelopoulos, M.; Thanos, D.; Mouzaki, A. Transcription Factor Ets-2 Acts as a Preinduction Repressor of Interleukin-2 (IL-2) Transcription in Naive T Helper Lymphocytes. J. Biol. Chem. 2016, 291, 26707-26721. [CrossRef] [PubMed] 